This is the author's final, peer-reviewed manuscript as accepted for publication. The publisher-formatted version may be available through the publisher's web site or your institution's library.

\title{
Single-copy gene fluorescence in situ hybridization and genome analysis: Acc-2 loci mark evolutionary chromosomal rearrangements in wheat
}

Tatiana V. Danilova, Bernd Friebe, Bikram S. Gill

How to cite this manuscript

If you make reference to this version of the manuscript, use the following information:

Danilova, T. V., Friebe, B., \& Gill, B. S. (2012). Single-copy gene fluorescence in situ hybridization and genome analysis: Acc-2 loci mark evolutionary chromosomal rearrangements in wheat. Retrieved from http://krex.ksu.edu

\section{Published Version Information}

Citation: Danilova, T. V., Friebe, B., \& Gill, B. S. (2012). Single-copy gene fluorescence in situ hybridization and genome analysis: Acc-2 loci mark evolutionary chromosomal rearrangements in wheat. Chromosoma, 121(6), 597-611.

Copyright: @ Springer-Verlag Berlin Heidelberg 2012

Digital Object Identifier (DOI): doi:10.1007/s00412-012-0384-7

Publisher's Link: http://link.springer.com/article/10.1007\%2Fs00412-012-0384-7

This item was retrieved from the K-State Research Exchange (K-REx), the institutional repository of Kansas State University. K-REx is available at http://krex.ksu.edu 


\title{
Single-copy gene fluorescence in situ hybridization and genome analysis: Acc- 2 loci mark evolutionary chromosomal rearrangements in wheat
}

Tatiana V. Danilova, Bernd Friebe, Bikram S. Gill

Wheat Genetic and Genomic Resources Center, Department of Plant Pathology, Kansas State University, Manhattan, KS 66506

\begin{abstract}
Fluorescent in situ hybridization (FISH) is a useful tool for physical mapping of chromosomes and studying evolutionary chromosome rearrangements. Here we report a robust method for single-copy gene FISH for wheat. FISH probes were developed from cDNA of cytosolic acetyl-CoA carboxylase gene (Acc-2) and mapped on chromosomes of bread wheat, Triticum aestivum $\mathrm{L}$. $(2 \mathrm{n}=6 \mathrm{x}=42$, AABBDD), and related diploid and tetraploid species. Another nine full-length cDNA FISH probes were mapped and used to identify chromosomes of wheat species. The Acc-2 probe was detected on the long arms of each of the homoeologous group-3 chromosomes (3A, 3B, and 3D), on 5DL and 4AL of bread wheat, and on homoeologous and nonhomoeologous chromosomes of other species. In the species tested, FISH detected more Acc2 gene or pseudogene sites than previously found by PCR and Southern hybridization analysis and showed presence/absence polymorphism of $A c c-2$ sequences. FISH with the $A c c-2$ probe revealed the 4A-5A translocation, shared by several related diploid and polyploid species and inherited from an ancestral A-genome species, and the T. timopheevii specific $4 \mathrm{~A}^{\mathrm{t}}-3 \mathrm{~A}^{\mathrm{t}}$ translocation.
\end{abstract}

Key words wheat, single-copy gene fluorescence in situ hybridization, acetyl-CoA carboxylase, karyotype evolution 


\section{Introduction}

Bread wheat, Triticum aestivum L., is an allohexaploid ( $2 \mathrm{n}=6 \mathrm{x}=42$, AABBDD) containing genomes of three species. Tetraploid wheats, $2 \mathrm{n}=4 \mathrm{x}=28$, with AABB (Emmer group) and $A^{t} A^{t} G G$ (Timopheevii group) genomes are the result of two separate hybridization events involving T. urartu Tumanian ex Gandilyan, the A-genome donor (Dvorak et al. 1993), and an outcrossing species closely related to the $\mathrm{S}$ genome of Aegilops speltoides Tausch, the ancestor of B and G genomes (Dvorak and Zhang 1990; Kilian et al. 2007). Hexaploid wheat arose from hybridization of cultivated emmer T. turgidum L. (AABB) (Nesbitt and Samuel 1996; Dvorak et al. 2004) and the D-genome donor Ae. tauschii Coss. (Kihara 1944; McFadden and Sears 1946; Dvorak et al. 1998).

The C- and N-banding karyotyping of bread wheat and its cultivated and wild relatives provided a foundation for analyzing the cytogenetic structure of the Triticeae (Gill et al. 1991; Friebe and Gill 1996). In situ hybridization with probes containing rye repeats (pSc119) were used to identify B-genome chromosomes (Rayburn and Gill 1985), and the Afa-family repeat from Ae. tauschii was used to identify the D-genome chromosomes (Rayburn and Gill 1987; Mukai et al. 1993). Fluorescence in situ hybridization (FISH) with probes containing a GAAsatellite sequence produced patterns similar to N-banding or C-banding on chromosomes of barley, rye, wheat, and Aegilops species (Gerlach 1977; Pedersen et al. 1996). Chromosome identification using repeated DNA probes is difficult because the abundance and distribution of repetitive elements can vary among homologous chromosomes within a species (Friebe and Gill 1994), or among chromosomes of closely related species (Badaeva et al. 1994; Dedkova et al. 2007).

A series of wheat aneuploid, deletion, and substitution lines have been used for gene mapping (Sears 1954; Endo and Gill 1996). The chromosome bin physical map of about 6,000 expressed sequence tags (ESTs) has been established using deletion stocks (Qi et al. 2004). 
However, the deletion bins are large in size and loci within the bins cannot be ordered physically.

Using single-copy gene FISH has the potential of fine physical mapping and ordering of genes along the chromosomes, including chromosomal regions with low recombination rates. In wheat, gene-specific probes and probes for tandem repeats, including oligonucleotide probes, were used in indirect FISH with blocking to detect tandem repeats and gene clusters (Mukai et al. 1993; Pedersen and Langridge 1997; Turner et al. 1999; Li et al. 2003; Turnbull et al. 2003; Szakacs and Molnar-Lang 2007; Cuadrado et al. 2008 a, b). Indirect FISH uses nonfluorescent chemicals for labeling and needs an additional detection step for visualizing the hybridization site and amplifying of the signal. Single gene probes also were used in FISH with tyramide signal amplification (Perez et al. 2009). These methods need blocking, detection, and signal amplification steps and have not been used widely.

BAC clones were used as FISH probes for genic regions in species with small genomes and a low content of repetitive elements, such as Arabidopsis (Lysak et al. 2001), Brachypodium (Febrer et al. 2010; Ma et al. 2010), rice (Jiang et al. 1994), and sorghum (Woo et al. 1994; Kim et al. 2002). Bread wheat has one of the largest plant genomes (17 Gb), containing about $90 \%$ repetitive sequences, $70 \%$ of which are transposable elements and a large fraction of microsatellites and tandem repeats (Li et al. 2004). BAC-FISH in wheat painted either all chromosomes over their entire length, produced a genome-specific painting, or painted clusters of tandem repeats depending on the content of repetitive sequences in a BAC clone (Zhang et al. $2004 a, b)$.

For genomes enriched with repeats, a repeat-free probe for a particular genic region either can be produced from cDNA or developed from genomic DNA by sequence analysis and PCR amplification of the repeat-free region, and used in direct FISH as was shown in maize (Wang et al. 2006; Lamb et al. 2007; Danilova and Birchler 2008) and barley (Ma et al. 2010). In direct 
FISH, fluorochromes are incorporated directly into DNA probes and the procedure does not need detection step.

As a model for probe development, we selected the wheat gene Acc-2 encoding cytosolic acetyl-CoA carboxylase (ACCase). Plants have two forms of ACCase; one is present in plastids, catalyzing the de novo synthesis of fatty acids and another in the cytosol, involved in the synthesis of very long-chain fatty acids and secondary metabolites such as flavonoids and anthocyanins. Distinct from other species, where plastid ACCase is composed of four subunits some of which are encoded by chloroplast genes, in grasses both plastid and cytosolic forms of ACCase are encoded by nuclear genes, $A c c-1$ and $A c c-2$, respectively (Sasaki and Nagano 2004). In wheat, the $A c c-1$ genes were mapped on the short arms of the group-2 chromosomes (Gornicki et al. 1997) and Acc-2 in the distal region of the long arm of the group-3 chromosomes and chromosome arm 5DL (Faris et al. 2001). A partly processed pseudogene $\Psi$-Acc-2 with more than $90 \%$ identity to the $A c c-2$ coding sequence was found in wheat, T. urartu, and $A e$. tauschii. Six different sequences of the $A c c-2$ gene and pseudogene are present in the wheat genome (Podkowinski et al. 1996; Huang et al. 2002); at least three of the Acc-2 genes are expressed equally in young leaves (Podkowinski et al. 2003) and their coding sequences $(6.3 \mathrm{~kb})$ have 98\% identity (Gornicki et al. 1994; Chalupska et al. 2008). The genes and pseodogenes are likely arranged in tandem repeats (Faris et al. 2001).

The objective of this research was to develop an $A c c-2$-specific probe and map Acc-2 on chromosomes of wheat and its diploid and tetraploid progenitor species using multicolor direct FISH. For individual chromosome identification, probes for tandem repeats and microsatellites were used. For chromosomes lacking these markers, chromosome-specific full-length cDNA FISH markers were developed. The present work demonstrates the usefulness of direct FISH for physical mapping of genic sequences and studying chromosome rearrangements and will have broad applications in genome analysis of the Triticeae. 


\section{Materials and methods}

Plant material

Seeds from the collection of Wheat Genetic and Genomic Resources Center, KSU, were used; Triticum aestivum, T. urartu, T. monococcum, Ae. speltoides, Ae. tauschii, T. turgidum subsp. dicoccoides (Körn. Ex Asch. \& Graebn.) Thell., T. turgidum subsp. dicoccum (Schrank) Thell., T. turgidum subsp. durum (Desf.) Husn., and T. timopheevii (Zhuk.) Zhuk. (Table 1); double ditelosomic (dDt) and aneuploid ditelosomic (Dt) lines of cv. 'Chinese Spring': CSdDt1A (TA3132), CSdDt2A (TA3133), CSdDt3A (TA3134), CSdDt5A (TA3136), CSdDt6A (TA3137), CSdDt1D (TA3158), CSdDt2D (TA3146), CSdDt3D (TA3147-2), CSdDt4D (TA3148-2), CSdDt5D (TA3149), CSdDt6D (TA3150), CSdDt7D (TA3151), CSDt7DS (TA3130), CSDt7DL (TA3171) and cv. 'Canthatch': CTH Dt7DS (TA3068), CTH Dt7DL (TA3069).

Slide preparation and FISH procedure

Somatic chromosome preparations using the drop technique, direct probe labeling by nick translation, and the FISH procedure were as described previously (Kato et al. 2004; Kato et al. 2006) with minor modifications. In brief, $2-3$ day-old root tips from germinated seeds (1.5-2.0 $\mathrm{cm}$ long) were cut and treated in a nitrous oxide gas chamber for $2 \mathrm{~h} 20 \mathrm{~min}$, fixed on ice in cold $90 \%$ acetic acid for $10 \mathrm{~min}$, washed and stored in $70 \%$ ethanol at $-20^{\circ} \mathrm{C}$. For slide preparation, roots were washed in tap water for $10 \mathrm{~min}$ and then in $\mathrm{KCl}$ buffer $5 \min (75 \mathrm{mM} \mathrm{KCl}, 7.5 \mathrm{mM}$ EDTA, pH 4); 3-5 meristems (1-2 mm long) were placed in $20 \mu 1$ of 4\% cellulase Onozuka R-10 (Yakult, Japan, Tokyo cat \# 201069), 1\% pectolyase Y23 (Karlan cat \# 8006) in KCl buffer, and incubated for $55 \mathrm{~min}$ at $37^{\circ} \mathrm{C}$. Digested meristems were washed for $5 \mathrm{~min}$ in ice-cold Tris- 
EDTA buffer, $\mathrm{pH} 7.6$, then three times in $100 \%$ ethanol. Meristems were dispersed by a needle in $15-25 \mu \mathrm{l}$ of ice-cold acetic acid - methanol mix (9:1) and immediately dropped on to precleaned glass slides placed in a humid chamber. Dried preparations were UV cross-linked and used for hybridization on the same day. The mixture of probes and the slide preparation were denatured at $100^{\circ} \mathrm{C}$ separately. Oligonucleotide probes were not treated at $100^{\circ} \mathrm{C}$ unless they were used in a mixture with nick-translated probes. Probe amounts per slide are given in Table 2. The rest of the FISH procedure and washes were the same as in Kato et al. (2006). Chromosome preparations were mounted and counterstained with 4',6-diamidino-2-phenylindole solution (DAPI) or propidium iodide (PI) in Vectashield (Vector Laboratories, cat \# H-1200, H-1300). Probe DNA was labeled with Fluorescein-12-dUTP (green) or Texas red-5-dCTP (red), (PerkinElmer, cat \# NEL413001EA and NEL426001EA). Images were captured with a Zeiss Axioplan 2 microscope using a cooled charge-coupled device camera CoolSNAP HQ2 (Photometrics) and AxioVision 4.8 software (Zeiss). Images were processed using the Adobe Photoshop software (Adobe Systems Incorporated, San Jose, CA, USA).

\section{Acc-2 FISH probes}

Sequences of the Acc-2 gene (U39321, chromosome 3AL) and cDNA (U10187, 3DL) were used to develop the probes. The gene sequence was analyzed with Repeatmasker software (Smit et al. 1996-2004), BLASTed against the Triticeae Repeat Sequence Database

(http://wheat.pw.usda.gov/ITMI/Repeats, (Altschul et al. 1997)), and the repeat-free gene regions and the cDNA sequence were used for primer design (Table S1, Fig. 1).

Three week-old leaves of Chinese Spring were used for DNA and RNA extraction. DNA was isolated using the sodium bisulfite method (Schweizer et al. 1995). RNA was extracted with Trizol Reagent (Invitrogen, cat \# 15596-026) according to the manufacturer's instructions. Selected $A c c-2$ gene regions were amplified via PCR with genomic DNA as a template using 
Sigma PCR reaction mix (Sigma, St. Louis, cat \# P0982). For Reverse Transcriptase-PCR, cDNAs were amplified using RT-PCR system with Platinum Taq High Fidelity polymerase (Invitrogen, cat \# 12574-030, 12574-035). PCR products of expected lengths were cut from 0.8 $\%$ agarose gel, purified with Qiagen Gel Extraction kit (cat. \# 28706) and reamplified with the same primers. The purified DNA was labeled with Texas red by nick translation and used as a probe. All PCR products were tested separately by FISH and those that showed no background were cloned using pGEM-T vector (Promega, cat \# A3600) and verified by sequencing. Plasmid inserts were amplified with standard primers (T7, Sp6), under standard conditions, purified with Invitrogene kit (cat \# K-3100-01) and used for pooled FISH probe.

Chromosome identification using FISH to tandem repeats

Oligonucleotide probes (Table 2) were developed using wheat tandem repeat sequences available in public databases and synthesized by Integrated DNA Technologies with a flourochrome attached to the 5'-end. The GAA oligonucleotide probe produced a FISH pattern similar to that of N-banding (Gill et al. 1991) on all B-genome chromosomes, all A-genome chromosomes except 1A, and on three pairs of D-genome chromosomes of wheat (Fig. 2a). Sequences of the D-genome-specific Afa-family repeat pAs1 (Nagaki et al. 1995; Nagaki et al. 1998) were used to design several oligonucleotide probes. Two of them showed D-genome-specific labeling and were combined (Table 2). The FISH pattern of the pAs1 oligonucleotide probes was verified on a set of seven D-genome double ditelosomic lines (Fig. S1). The physically shorter arm of chromosome 7D is homeologous to the long arms of chromosomes 7A and 7B (Werner et al. 1992; Friebe et al. 1996). To verify the arm-specific GAA and pAs1 FISH patterns for chromosome 7D, ditelosomic Dt7DS and Dt7DL lines of Canthatch and Chinese Spring were used (Fig. S2). The D-genome karyotype is shown in Fig. 2 b. 
Additional oligonucleotide probes were developed for the 45S- and 5S rDNA-tandem repeats of bread wheat (Table 2, Fig. S3). For labeling the nucleolus organizing region (NOR) rRNA loci of wheat relatives, clone pTa71, containing a 9-kb insertion with $18 \mathrm{~S}, 5.8 \mathrm{~S}$, and $26 \mathrm{~S}$ rRNA wheat genes and intergenic spacers (Gerlach and Bedbrook 1979) was used as a probe.

Chromosome identification using full-length cDNAs

The wheat full-length (FL) cDNAs (Kawaura et al. 2009) used in this study were supplied by the National BioResource Project-Wheat, Japan (http://www.nbrp.jp). Long ( $>3 \mathrm{~kb})$, FLcDNAs were selected from the Triticeae Full-Length cDNA database (TriFLDB) (Mochida et al. 2009). The chromosomal positions of selected cDNAs were detected by BLAST against expressed sequence tags (ESTs) mapped in the deletion bins of Chinese Spring (Qi et al. 2004; GrainGenes Database http://wheat.pw.usda.gov). FLcDNAs mapped on chromosomes of homoeologous groups 1, 3, 4, and 5 (Table 3) were selected, and the positions of the FLcDNA probes were verified by FISH on Chinese Spring chromosomes. Those probes that showed bright signals at the expected positions with no background were used to identify chromosomes of other species.

\section{Results}

Development of Acc-2 FISH probe

The Acc-2 gene should be an easily detectable FISH target because of its large size (transcribed part is $12.3 \mathrm{~kb}$ long, with $6.8 \mathrm{~kb}$ of coding sequence) (Chalupska et al. 2008). PCR primers were designed to produce a pooled FISH probe with a size of 5-6 kb (Table S1). Probes produced by PCR with genomic DNA as a template showed background hybridization to all chromosomes (Fig. S4) except for probe 3g, which did not include any introns. Apparently, despite sequence 
analysis, some repetitive elements were not detected in Acc-2 introns because of incompleteness in the wheat repeat databases. PCR products $1 \mathrm{c}, 2 \mathrm{c}$, and 3c (Table 2, Fig. 1) produced by RTPCR showed no background when used as FISH probes. They were cloned, verified by sequencing, and showed $97-100 \%$ similarity to the $A c c-2$ cDNA U10187. The pooled probe with a total length of 5,970 bp, containing the mixture of $1 \mathrm{c}, 2 \mathrm{c}$ and $3 \mathrm{c}$, PCR products, detected Acc-2 loci on the long arms of chromosomes 3A, 3B, 3D, 4A and 5D of Chinese Spring (Fig. 2c), Wichita, and TAM107. No FISH signals were detected on the short arms of the group-2 chromosomes (Fig. S5), where the Acc-1 gene was mapped (Gornicki et al. 1997).

\section{Full-length cDNA FISH probes}

Some chromosomes of diploid wheat and T. timopheevii with Acc-2 signals could not be distinguished based on their morphology, NOR site, or GAA pattern. To identify these chromosomes, FLcDNAs were selected from the TriFLDB database by sequence similarity to mapped ESTs. Each of the FLcDNA FISH probes hybridized to the expected positions on the three homoeologous chromosomes of the A, B and D genomes of Chinese Spring. An exception was FLcDNA 5S-1 (tplb0027f03), which showed 98\% similarity to the sequence of EST mapped on group-3 chromosomes but hybridized to the short arms of chromosomes of group-5 (Table 3). Because FLcDNA clones were checked only by PCR to verify the size of the inserts but were not verified by sequencing, the FLcDNA 5S-1 clone may contain a wrong insert. In total, we produced nine FLcDNA chromosome-specific FISH markers; one or two markers for each arm of group-1, -4 and -5 chromosomes and one marker for the short arm of group-3 chromosomes. The size of the FLcDNA FISH probes ranged from 1,491 bp to 5,094 bp (Table 3).

Development of FISH karyotypes and mapping of Acc-2 genes on chromosomes of wheat and Aegilops species 
For developing FISH karyotypes, probes pTa71 and the GAA- or pAs1-oligonucleotide were used and the patterns and morphologies were compared with existing $\mathrm{C}$ - or $\mathrm{N}$ - banding karyotypes. To map Acc-2, the pooled Acc-2 probe was hybridized together with GAA- or pAs1oligonucleotide probes. If it was not possible to identify chromosomes using the repeats, the oligonucleotide probes or the $A c c-2$ probe were combined with chromosome-specific FLcDNA probes in multicolor FISH.

A-genome diploids Although the morphology and C-banding pattern of chromosomes of T. monococcum and T. urartu were reported to be similar to those of the A-genome chromosomes of T. turgidum and T. aestivum (Friebe and Gill, 1996), their GAA banding was different in the accessions analyzed. All A-genome chromosomes of bread wheat have specific GAA signals except chromosome 1A (Fig. 2a). In T. urartu, we found two chromosome pairs with some minor GAA signals, one chromosome pair with the NOR signal and one with both, the NOR and a bright GAA signal (Fig. 3a). However it was not possible to determine their homeology unambiguously. In T. monococcum, only chromosome 4A can be distinguished by a bright GAA signal near the centromere (Friebe and Gill 1996). Minor GAA signals were detected on chromosomes which might be either $2 \mathrm{~A}$ or $3 \mathrm{~A}$ and on NOR chromosomes $1 \mathrm{~A}$ or $5 \mathrm{~A}$ (Fig. 3c).

We observed three chromosome pairs with Acc-2 FISH sites in both T. urartu and T. monococcum. In T. urartu, Acc-2 signals were detected on the long arm of a chromosome with the NOR site and bright GAA signal on the short arm near the centromere, which could be either chromosome $1 \mathrm{~A}$ or $5 \mathrm{~A}$; on a small metacentric chromosome with no GAA signals, which could be either $4 \mathrm{~A}$ or $6 \mathrm{~A}$; and on a larger submetacentric chromosome with a minor GAA signal on the short arm, which could be either $2 \mathrm{~A}$ or $3 \mathrm{~A}$ based on size, arm ratio, and the absence of the NOR site (Fig. 3a, b). Using FLcDNA probes, the chromosomes with Acc-2 loci were identified as 1A, 3A and 4A (Fig. 4a). 
In T. monococcum, the Acc-2 FISH sites were detected on chromosome 4A with the bright proximal GAA signal. Two other chromosome pairs with $A c c-2$ foci were identified with FLcDNA FISH markers as 1A, and 3A. (Fig. 3c, d; Fig. 4b). Thus, both diploid Triticum species have Acc-2 FISH loci on homologous chromosome arms 1AL, 3AL, and 4AL.

Ae. speltoides (SS) Two accessions of Ae. speltoides were analyzed by FISH. The GAA-FISH pattern identified all seven pairs of chromosomes. The accession TA2368 had five Acc-2 FISH sites: four on the long arms of chromosomes $3 \mathrm{~S}$ and $5 \mathrm{~S}$ and one on the long arm of one chromosome 1S (Fig. 3e, f). Another accession, TA2780, had four Acc-2 FISH sites on the long arms of chromosome pairs $3 \mathrm{~S}$ and $5 \mathrm{~S}$.

Ae. tauschii (DD) The chromosomes of Ae. tauschii were identified using the FISH karyotype of the $\mathrm{D}$ genome of bread wheat. However, chromosome 5D differed from 5D of wheat by the presence of the NOR. Acc-2 loci were detected on Ae. tauschii chromosome arms 3DL and 5DL (Fig. 3g, h).

AB-genome tetraploids The chromosomes of both wild and cultivated tetraploid accessions were identified by their GAA-FISH patterns, which are similar to those of the A- and Bchromosomes of T. aestivum. We tested four T. turgidum subsp. dicoccoides accessions of different geographic origins (Table 1). All were polymorphic in the number of Acc-2 FISH sites and their distribution. In the accession TA73 (Lebanon) and TA1392 (Israel), five Acc-2 loci were detected, two in the A-genome chromosome arms $3 \mathrm{AL}$ and $4 \mathrm{AL}$ and three on the Bgenome chromosome arms 1BL, 3BL, and 5BL (Fig. 3 i, j). In the accessions TA1385 (Iraq) and TA84 (Turkey), four Acc-2 loci were detected on chromosome arms 3AL, 4AL, 3BL, and 5BL.

In T. turgidum subsp. dicoccum, four Acc-2 loci were detected on chromosome arms 3AL, 4AL, 1BL, and 3BL. In three cultivars of T. turgidum subsp. durum, we detected three Acc-2 loci on chromosome arms 3AL, 4AL, and 3BL (Fig. 3k, Table 1).

T. timopheevii (At $\mathbf{A}^{\mathrm{t}} \mathrm{GG}$ ) Some chromosomes of $\mathrm{A}^{\mathrm{t}}$ genome of T. timopheevii can be distinguished by their GAA-FISH patterns (2A, 7A), NOR site (6A), and by their size and arm 
ratios (1A). G-genome chromosomes have specific GAA-FISH pattern, differ in size and arm ratio, and can be distinguished using a generalized C-banding karyotype of $T$. timopheevii subsp. araraticum Jakubz., a wild relative of T. timopheevii (Badaeva et al. 1994). Five chromosome pairs, two belonging to the $\mathrm{A}^{\mathrm{t}}$ genome and three to the G genome, had Acc-2 loci on their long arms. Chromosome $1 \mathrm{~A}^{\mathrm{t}}$ is the smallest in the $\mathrm{A}^{\mathrm{t}}$ genome and was identified on this basis. The second, a submetacentric chromosome with two clearly distinguishable Acc-2 FISH signals, could be either $3 \mathrm{~A}^{\mathrm{t}}, 4 \mathrm{~A}^{\mathrm{t}}$, or $5 \mathrm{~A}^{\mathrm{t}}$. The G-genome chromosomes with Acc-2 signals were similar to $1 \mathrm{G}, 3 \mathrm{G}$, and $5 \mathrm{G}$ of $T$. timopheevii subsp. araraticum. FLcDNA FISH probes were used to identify these chromosomes, although, the T. timopheevii specific rearrangements can hamper this approach. Translocations T1GS/6A ${ }^{t} S$, T1GS/4GS, T4GS/4A ${ }^{t} L$ and T4A ${ }^{t} L / 3 A^{t} L$ were shown to be present in distinct wild populations and cultivated T. timopheevii (Gill and Chen 1987; Jiang and Gill 1994; Maestra and Naranjo 1999; Rodriguez et al. 2000). Unlike Acc-2, the FLcDNA FISH probes used in our experiment were mapped in regions that are not involved in these translocations (Table 3), thus, allowing unambiguous identification of T. timopheevii chromosomes. The chromosome arms with Acc-2 FISH signals were identified as $1 \mathrm{~A}^{t} \mathrm{~L}, 4 \mathrm{~A}^{\mathrm{t}} \mathrm{L}$ (two distinct Acc-2 loci), 1GL, 3GL, and 5GL (Fig. 3 1, m, Fig. 4c).

In some chromosomal spreads of different species, it was possible to distinguish two closely located Acc-2 FISH signals: on chromosome arms 3AL and 3DL of Chinese Spring, 4AL of Wichita, 3BL and 3DL of TAM107, 3AL of T. urartu and 3DL of Ae. tauschii (Fig. S6, Table 1).

\section{Discussion}

Single-copy gene FISH and oligonucleotide probes for wheat genome analysis 
Here we report a fast and reliable single-copy gene FISH technique for wheat using nitrous oxide gas treatment for arresting cells at metaphase, the drop technique for somatic chromosome preparation, and direct probe labeling by nick translation (Kato et al. 2004; Kato et al. 2006). This procedure does not need detection and blocking steps, which were previously being used in indirect FISH to visualize gene clusters and repeats (Mukai et al. 1993; Pedersen and Langridge 1997; Turner et al. 1999; Li et al. 2003; Turnbull et al. 2003; Szakacs and Molnar-Lang 2007; Cuadrado et al. 2008a, b) or a signal-amplification step in tyramide-FISH (Perez et al. 2009). The direct FISH technique is sensitive enough to detect cDNA probes with a size of $3 \mathrm{~kb}$ on wheat somatic chromosomes (Fig. 4, Table 3). Cheap and reliable oligonucleotide FISH probes can be used for chromosome identification and detecting large-scale chromosomal rearrangements in the Triticeae or can be combined with single-copy gene probes in multicolor direct FISH for studying small-scale rearrangements and fine mapping.

FISH mapping of $A c c-2$ genes

The Acc-2 gene was mapped by Southern hybridization analysis of wheat aneuploid and deletion stocks on chromosomes 3A, 3B, 3D, and 5D of T. aestivum and by linkage mapping on chromosomes 3DL and 5DL of Ae. tauschii (Faris et al. 2001). In TAM107, six copies of the Acc-2 gene or pseudogene sequences were found by PCR cloning and DNA sequence analysis. Two copies of the gene and one pseudogene were found in diploid T. urartu and T. monococcum; two copies of the gene were found in Ae. speltoides, and one gene and one pseudogene were found in Ae. tauschii. In the tetraploid species T. turgidum subsp. dicoccoides and T. timopheevii, three copies of the Acc-2 gene or pseudogene sequences were isolated (Faris et al. 2001; Huang et al. 2002), (Table 1). We applied FISH mapping to the same accessions of wheat and Aegilops species, except for T. urartu and some additional accessions. 
In the present study, $A c c-2$ cDNA was used as a FISH probe. The sequences of $A c c-1$ and Acc-2 cDNAs (U10187 and AF029895) are approximately 73\% similar when compared by NCBI BLASTN (Altschul et al. 1997). Three Acc-1 loci were mapped on the short arms of the group-2 chromosomes and on 2DS of Ae. tauschii (Gornicki et al. 1997). The stringency of FISH with the Acc-2 cDNA pooled probe based on the GC content of the probe, the hybridization and washing temperatures, and buffer composition is $65-70 \%$ (Schwarzacher and Heslop-Harrison 2000). We did not observe any FISH signals on group-2 chromosomes of bread wheat or Ae. tauschii; hence, our hybridization stringency is higher than $73 \%$ and sensitive enough to distinguish between the $A c c-1$ and $A c c-2$ sequences.

FISH revealed $A c c-2$ loci on chromosome arm 4AL of bread wheat in three cultivars with distinct pedigrees and additional copies of Acc-2 genes or pseudogenes were found in other genomes: three versus two in Ae. speltoides, and five versus three in T. turgidum subsp. dicoccoides and T. timopheevii (Table 1). The FISH resolution on condensed mitotic chromosomes is not very high. The axial resolution of FISH on maize somatic chromosome is 3$8 \mathrm{Mb}$, but it is possible to distinguish separate FISH signals that are about $200 \mathrm{~kb}$ apart (Danilova and Birchler 2008). Double Acc-2 FISH signals were observed on chromosomes 3A, 3D, 3B, and 4A of bread wheat; 4A $\mathrm{t}^{\mathrm{t}}$ and 3G of T. timopheevii; and 3D of Ae. tauschii (Fig. S6), indicating that on some chromosomes, Acc-2 genes or pseudogenes are arranged in tandem repeats, which agrees with previous studies (Faris et al. 2001; Huang et al. 2002). Thus, the total number of undetected $A c c-2$ gene or pseudogene copies may even be higher. In polyploid species, the PCR cloning approach and Southern hybridization analysis may not detect copies of homoeologous or orthologous genes because of sequence divergence or high sequence identity (Feuillet et al. 2001; Huang et al. 2002; Caldwell et al. 2004). FISH can help in mapping and evaluating the copy number of these genes.

Change of Acc-2 chromosome location and copy number during Triticeae evolution 
Genomes of newly formed allopolyploids are prone to rapid changes leading to cytological, genetic and epigenetic diploidization through elimination of DNA sequences, gene silencing or changing functions of homeologous genes (Dvorak et al. 2004; Pumphrey et al. 2009). Locus deletions followed polyploidization event happen more frequently at the distal ends of wheat chromosomes with high recombination rate (Dvorak et al. 2004). Some synteny perturbations between wheat homoeologous chromosomes originated at the diploid level. However, the homoeologous genomes of young allopolyploid species like T. aestivum are still largely collinear i.e. composed of homoeologous genes at equivalent positions along the chromosomes (Feuillet et al. 2001; Akhunov et al. 2003).

We observed that the number of Acc-2 loci varied from two to five and some consisted of tandemly organized, duplicated copies (Table 1). We detected the Acc-2 FISH signals on the long arm of group- 1, 3, and 5 chromosomes of S-genome of Ae. speltoides (TA2368); the B genome of T. turgidum subsp. dicoccoides and the G genome of T. timopheevii; on the long arms of chromosome 1A and 3A of T. urartu and T. monococcum; $1 \mathrm{~A}^{\mathrm{t} L}$ of T. timopheevii; and on the 3DL and 5DL of Ae. tauschii and T. aestivum. In barley, two copies of Acc-2 gene were found (Faris et al. 2001). By comparing the wheat Acc-1 and Acc-2 cDNA sequences (AF029895 and U10187) against the genome sequence of barley (VIROBLAST (Deng et al. 2007), http://webblast.ipk-gatersleben.de/barley/viroblast.php), we found one sequence with $95 \%$ similarity to wheat $A c c-1$ on barley chromosome arm $2 \mathrm{HS}$ and two sequences with $96 \%$ and $90 \%$ similarity to wheat $A c c-2$ on chromosomes arms $3 \mathrm{HL}$ and 5HL, respectively. Barley chromosomes are highly collinear to the corresponding wheat chromosomes (Dubcovsky et al. 1996). The comparison of the wheat $A c c-1$ and $A c c-2$ sequence with the rice genome (NCBI BLASTN (Zhang et al. 2000)) detected a sequence similar to Acc-1 on the long arm of rice chromosome 5 and to $A c c-2$ on the long arm of rice chromosome 10. Both rice chromosomes are homologous to the group-1 chromosomes of wheat (Sorrells et al. 2003). Based on these data and 
our FISH mapping results, we assume that the original location of multicopy Acc-2 genes in the diploid progenitor of Triticeae was on the long arm of chromosomes 1, 3, and 5 (Fig. 5).

4AL/5AL translocation In the A genome of all diploid and polyploid species tested in this study, Acc-2 loci were detected on chromosome arm 4AL but not on 5AL. Chromosome 4A of T. monococcum, T. turgidum, and bread wheat is known to have a rearranged structure that resulted from a 4AL/5AL translocation, which occurred at the diploid level. Further rearrangements involving chromosome arms 7BS, a paracentric and two pericentric inversions, took place at the tetraploid level (Naranjo et al. 1987; Devos et al. 1995; Mickelson-Young et al. 1995; Miftahudin et al. 2004). Our results confirm the presence of the A-genome-specific translocation T4AL/5AL that is shared by several related species and is also present in the derived A genomes of allopolyploid species (Jiang and Gill 1994; Rodriguez et al. 2000) (Fig. 5).

$\mathbf{3 A}^{\mathbf{t}} \mathbf{L} / \mathbf{4 A}^{\mathbf{t}} \mathbf{L}$ translocation $A c c-2$ FISH signals in T. timopheevii were observed on chromosome arms $1 \mathrm{~A}^{t} \mathrm{~L}$ and $4 \mathrm{~A}^{t} \mathrm{~L}$, similar to the A-genome progenitor species but were absent on chromosome arm $3 \mathrm{~A}^{t} \mathrm{~L}$ and duplicated on $4 \mathrm{~A}^{\mathrm{t}} \mathrm{L}$. According to Maestra and Naranjo (1999) and Rodriguez et al. (2000), one of the T. timopheevii species-specific translocations involved chromosome arms $4 \mathrm{~A}^{t} \mathrm{~L}$ and $3 \mathrm{~A}^{\mathrm{t}} \mathrm{L}$. Therefore, of the two distal Acc-2 loci detected on the chromosome arm $4 \mathrm{~A}^{\mathrm{t}} \mathrm{L}$, the proximal FISH site marks the 5AL segment and the distal signal marks the 3AL segment. This Timopheevii lineage-specific chromosome can be described as T4 $A^{t} S \cdot 4 A^{t} L-5 A^{t} L-3 A^{t} L$. The presence of a $3 A^{t} L$ segment on $T 4 A^{t} S \cdot 4 A^{t} L-5 A^{t} L-3 A^{t} L$ is also indicated by the high metaphase I pairing of this segment with the $3 \mathrm{AL}$ arm of T. turgidum (Rodriguez et al. 2000).

It is likely that as a result of a reciprocal translocation the distal $5 \mathrm{~A}^{\mathrm{t}} \mathrm{L}$ segment of T4 $A^{t} S \cdot 4 A^{t} L-5 A^{t} L$ was translocated to the distal end of the $3 A^{t} L$ arm, and chromosome $3 A^{t}$ can be described as T3A $A^{t} 3 A^{t} L-5 A^{t} L$. Two lines of evidence support this hypothesis. Rodriguez et al. (2000) observed very low pairing between $3 \mathrm{AL}$ of $T$. turgidum with $3 \mathrm{~A}^{\mathrm{t}} \mathrm{L}$ of $T$. timopheevii. It 
has been shown previously that non-homology at the distal ends leads to a drastic reduction in meiotic metaphase I pairing (Curtis and Lukaszewski, 1991; Gill and Friebe, 1998). In addition, Gill and Chen (1987) observed that chromosome 4A ${ }^{\mathrm{m}}$ (T4AS 4AL-5AL) of T. monococcum paired in the form of a quadrivalent with chromosome 3A (3AS 3AL) of T. turgidum and chromosomes $3 A^{t}\left(T 3 A^{t} S \cdot 3 A^{t} L-5 A^{t} L\right)$ and $4 A^{t}\left(T 4 A^{t} S \cdot 4 A^{t} L-5 A^{t} L-3 A^{t} L\right)$ of T. timopheevii in $23.3 \%$ of the pollen mother cells analyzed. This configuration is only possible if $3 \mathrm{~A}^{\mathrm{t}}$ is, in fact, a translocation chromosome $T 3 \mathrm{~A}^{\mathrm{t}} \mathrm{S} \cdot 3 \mathrm{~A}^{\mathrm{t}} \mathrm{L}-5 \mathrm{~A}^{\mathrm{t}} \mathrm{L}$.

S, B, G genome polymorphism Ae. speltoides, the putative donor of the $\mathrm{B}$ and $\mathrm{G}$ genomes in $\mathrm{AABB}$ and $\mathrm{A}^{\mathrm{t}} \mathrm{A}^{\mathrm{t}} \mathrm{GG}$ tetraploids, is a cross-pollinating species and has the highest level of diversity compared with other diploid species (Kilian et al. 2007). The S genome of Ae. speltoides and $\mathrm{B} / \mathrm{G}$ genomes of tetraploid species were polymorphic for the Acc-2 FISH pattern. The Ae. speltoides TA2368 (Turkey) had five Acc-2 FISH signals, four on the 3SL and 5SL arms and one on the chromosome arm 1SL. Ae. speltoides TA2780 (Israel) had Acc-2 loci on chromosome arms 3SL and 5SL. In the B and G genomes of wild T. turgidum subsp. dicoccoides, TA73 (Lebanon), TA1392 (Israel), and T. timopheevii, Acc-2 loci were detected on three chromosome pairs of group 1, 3, and 5. In two other T. turgidum subsp. dicoccoides accessions, from Iraq and Turkey, Acc-2 loci were present on 3BL and 5BL. In cultivated $T$. turgidum subsp. dicoccum TA10492 (Ethiopia), the Acc-2 FISH signals were detected on 1BL and 3BL. It is interesting to note that the T. turgidum subsp. dicoccoides accessions with similar Acc-2 distribution have similar geographic origin, either western (Israel, Lebanon) or centraleastern (Iraq, Turkey). The origin of the Emmer wheat in Ethiopia is unknown. The wild Emmer from the central-eastern group is closer to cultivated populations (reviewed in Nesbitt and Samuel 1996; Haudry et al. 2007). In three cultivars of domesticated T. turgidum subsp. durum and T. aestivum, the Acc-2 FISH signal was detected only on chromosome arm 3BL (Table 1). The ancestors of T. turgidum and T. timopheevii originated as a result of independent polyploidization events involving Ae. speltoides as a source of the $\mathrm{G}$ and $\mathrm{B}$ genomes and 
T. urartu as a source of the A genome (Jiang and Gill 1994; Rodriguez et al. 2000; Kilian et al. 2007). Hexaploid wheat has no wild form; it originated as a hybrid of cultivated T. turgidum and Ae. tauschii (McFadden and Sears 1946; Dvorak et al. 2004; reviewed in Matsuoka 2011).

Whether or not chromosomes $1 \mathrm{BL}$ and $5 \mathrm{BL}$ of $T$. turgidum were involved in rearrangements that resulted in the loss of Acc-2 loci in wild and domesticated Emmer or different forms of Ae. speltoides were involved in several hybridization events in western and central eastern regions resulting in polymorphic $\mathrm{AABB}$ tetraploids is unknown.

\section{Conclusions}

1. Oligonucleotide probes were found to be useful for identifying chromosomes of bread wheat and related tetraploid and diploid species except the A genomes of T. urartu, $T$. monococcum, and T. timopheevii, which do not have enough tandemly organized GAA and pAs1 repeats detectable by direct FISH.

2. Single-gene probes were developed from wheat cDNAs and used for identifying chromosome arms and mapping genes by direct FISH. Currently, we are developing a set of single-gene FISH markers that will cover all wheat chromosome arms.

3. The PCR approach, with genome-specific primers, or Southern hybridization analysis sometimes may not reveal all copies of genes or pseudogenes in polyploid species. FISH with Acc-2 probe revealed the presence of additional $A c c-2$ copies in $\mathrm{A}, \mathrm{B}, \mathrm{D}$, and $\mathrm{G}$ genomes in the Triticeae.

4. The distribution of Acc-2 loci, representing a multigene family on chromosomes of A, B, G, S, and D genomes of the analyzed species was variable, showed that the collinearity of the genomes is not perfect. On the other hand, genes present as a single locus in each genome can be a reliable chromosome landmark, as was shown for nine FLcDNAs.

5. FISH with the $A c c-2$ probe revealed the presence of chromosome rearrangements that originated at the diploid or tetraploid level and are shared by several related species. The A- 
genome specific 4AL-5AL translocation was detected in diploid and polyploid species including both the Emmer and Timopheevii groups, and the $4 \mathrm{~A}^{t} \mathrm{~L}-3 \mathrm{~A}^{\mathrm{t}} \mathrm{L}$ translocation was detected in $T$. timopheevii. Thus, single-copy gene FISH, along with other methods, can be a useful tool in phylogenetic and evolutionary studies.

Acknowledgments We thank W. John Raupp for editing of the manuscript, Duane Wilson for excellent technical assistance, and Dr. Sunish Sehgal for help with the sequencing. This research was supported by grants from the Kansas Wheat Commission and the Kansas Crop Improvement Association. This is contribution number 13-029-J from the Kansas Agricultural Experiment Station, Kansas State University, Manhattan, KS 66506-5502, U.S.A. 


\section{References}

Akhunov ED, Akhunova AR, Linkiewicz AM, Dubcovsky J, Hummel D, Lazo G, Chao SM, Anderson OD, David J, Qi LL, Echalier B, Gill BS, Gustafson MJP, La Rota M, Sorrells ME, Zhang DS, Nguyen HT, Kalavacharla V, Hossain K, Kianian SF, Peng JH, Lapitan NLV, Wennerlind EJ, Nduati V, Anderson JA, Sidhu D, Gill KS, McGuire PE, Qualset CO, Dvorak J (2003) Synteny perturbations between wheat homoeologous chromosomes caused by locus duplications and deletions correlate with recombination rates. Proc Natl Acad Sci USA 100:10836-10841. doi:10.1073/pnas.1934431100

Altschul SF, Madden TL, Schaffer AA, Zhang JH, Zhang Z, Miller W, Lipman DJ (1997) Gapped BLAST and PSI-BLAST: a new generation of protein database search programs. Nucleic Acids Res 25:3389-3402. doi:10.1093/nar/25.17.3389

Badaeva ED, Badaev NS, Gill BS, Filatenko AA (1994) Intraspecific karyotype divergence in Triticum araraticum (Poaceae). Plant Syst and Evol 192:117-145. doi: 10.1007/BF00985912

Barker RF, Harberd NP, Jarvis MG, Flavell RB (1988) Structure and evolution of the intergenic region in a ribosomal DNA repeat unit of wheat. J Mol Biol 201:1-17. doi:org/10.1016/00222836(88)90434-2

Caldwell KS, Dvorak J, Lagudah ES, Akhunov E, Luo MC, Wolters P, Powell W (2004) Sequence polymorphism in polyploid wheat and their D genome diploid ancestor. Genetics 167:941947. doi:10.1534/genetics.103.016303

Chalupska D, Lee HY, Faris JD, Evrard A, Chalhoub B, Haselkorn R, Gornicki P (2008) Acc homoeoloci and the evolution of wheat genomes. Proc Natl Acad Sci USA 105:9691-9696. doi:10.1073/pnas.0803981105

Cuadrado A, Cardoso M, Jouve N (2008a) Increasing the physical markers of wheat chromosomes using SSRs as FISH probes. Genome 51:809-815. doi:10.1139/G08-065 
Cuadrado A, Cardoso M, Jouve N (2008b) Physical organisation of simple sequence repeats (SSRs) in Triticeae: structural, functional and evolutionary implications. Cytogenet Genome Res 120:210-219. doi:10.1159/000121069

Curtis CA, Lukaszewski AJ (1991) Metaphase I pairing of deficient chromosomes and genetic mapping of deficiency breakpoints in common wheat. Genome 34:553-560. doi: $10.1139 / \mathrm{g} 91-085$

Danilova TV, Birchler JA (2008) Integrated cytogenetic map of mitotic metaphase chromosome 9 of maize: resolution, sensitivity, and banding paint development. Chromosoma 117:345-356. doi:10.1007/s00412-008-0151-y

Dedkova OS, Badaeva ED, Mitrofanova OP, Bilinskaya EN, Pukhalskiy VA (2007) Analysis of intraspecific diversity of cultivated emmer Triticum dicoccum (Schrank.) Schuebl. using Cbanding technique. Russ J of Genetics 43:1271-1285. doi:10.1134/S1022795407110105

Deng W, Nickle DC, Learn GH, Maust B, Mullins JI (2007) ViroBLAST: a stand-alone BLAST web server for flexible queries of multiple databases and user's datasets. Bioinformatics 23:2334-2336. doi:10.1093/bioinformatics/btm331

Devos KM, Dubcovsky J, Dvorak J, Chinoy CN, Gale MD (1995) Structural evolution of wheat chromosomes 4A, 5A, and 7B and its impact on recombination. Theor Appl Genet 91:282288. doi: 10.1007/BF00220890

Dubcovsky J, Luo MC, Zhong GY, Bransteitter R, Desai A, Kilian A, Kleinhofs A, Dvorak J (1996) Genetic map of diploid wheat, Triticum monococcum L. and its comparison with maps of Hordeum vulgare L. Genetics 143:983-999

Dvorak J, Zhang HB (1990) Variation in repeated nucleotide sequences sheds light on the phylogeny of the wheat B and G genomes. Proc Natl Acad Sci USA 87:9640-9644

Dvorak J, Diterlizzi P, Zhang HB, Resta P (1993) The evolution of polyploid wheats: identification of the A genome donor species. Genome 36:21-31. doi 10.1139/g93-004 
Dvorak J, Luo MC, Yang ZL, Zhang HB (1998) The structure of the Aegilops tauschii genepool and the evolution of hexaploid wheat. Theor Appl Genet 97:657-670

Dvorak J, Yang ZL, You FM, Luo MC (2004) Deletion polymorphism in wheat chromosome regions with contrasting recombination rates. Genetics 168:1665-1675. doi:10.1534/genetics.103.024927

Endo TR, Gill BS (1996) The deletion stocks of common wheat. J Hered 87:295-307. doi: 00221503/96/J5.00

Faris J, Sirikhachornkit A, Haselkorn R, Gill B, Gornicki P (2001) Chromosome mapping and phylogenetic analysis of the cytosolic acetyl-CoA carboxylase loci in wheat. Mol Biol Evol $18: 1720-1733$

Febrer M, Goicoechea JL, Wright J, McKenzie N, Song XA, Lin JK, Collura K, Wissotski M, Yu Y, Ammiraju JSS, Wolny E, Idziak D, Betekhtin A, Kudrna D, Hasterok R, Wing RA, Bevan MW (2010) An integrated physical, genetic and cytogenetic map of Brachypodium distachyon, a model system for grass research. PLoS ONE 5:1-10. doi:10.1371/journal.pone.0013461

Feuillet C, Penger A, Gellner K, Mast A, Keller B (2001) Molecular evolution of receptor-like kinase genes in hexaploid wheat. Independent evolution of orthologs after polyploidization and mechanisms of local rearrangements at paralogous loci. Plant Physiol 125:1304-1313. doi:10.1104/pp.125.3.1304

Friebe B, Kim NS, Kuspira J, Gill BS (1990) Genetic and cytogenetic analyses of the a-genome of Triticum monococcum .6. Production and identification of primary trisomics using the Cbanding technique. Genome 33:542-555. doi: 10.1139/g90-081

Friebe B, Gill BS (1994) C-band polymorphism and structural rearrangements detected in common wheat (Triticum aestivum). Euphytica 78:1-5 
Friebe BR, Gill BS (1996) Chromosome banding and genome analysis in diploid and cultivated polyploid wheats. Methods of genome analysis in plants. CRC Press, Boca Raton

Friebe BR, Jellen EN, Gill BS (1996) Verification of the identity of the Chinese Spring ditelosomic stocks Dt7DS and Dt7DL. Wheat Inf Serv 83:31-32

Friebe B, Qi LL, Nasuda S, Zhang P, Tuleen NA, Gill BS (2000) Development of a complete set of Triticum aestivum-Aegilops speltoides chromosome addition lines. Theor Appl Genet $101: 51-58$

Gerlach WL (1977) N-banded karyotypes of wheat species. Chromosoma 62:49-56. doi: 10.1007/BF00328439

Gerlach WL, Bedbrook JR (1979) Cloning and characterization of ribosomal RNA genes from wheat and barley. Nucleic Acids Res 7:1869-1885. doi:10.1093/nar/7.7.1869

Gill BS, Chen PD (1987) Role of cytoplasm-specific introgression in the evolution of the polyploid wheats. Proc Natl Acad Sci USA 84:6800-6804

Gill BS, Friebe B, Endo TR (1991) Standard karyotype and nomenclature system for description of chromosome bands and structural-aberrations in wheat (Triticum aestivum). Genome 34:830839. doi: $10.1139 / \mathrm{g} 91-128$

Gill BS, Friebe B (1998) Plant cytogenetics at the dawn of the $21^{\text {st }}$ century. Curr Opinion Plant Biol $1: 109-115$

Gornicki P, Podkowinski J, Scappino LA, DiMaio J, Ward E, Haselkorn R (1994) Wheat acetylcoenzyme A carboxylase: cDNA and protein structure. Proc Natl Acad Sci USA 91:68606864

Gornicki P, Faris J, King I, Podkowinski J, Gill B, Haselkorn R (1997) Plastid-localized acetyl-CoA carboxylase of bread wheat is encoded by a single gene on each of the three ancestral chromosome sets. Proc Natl Acad Sci USA 94:14179-14184 
Haudry A, Cenci A, Ravel C, Bataillon T, Brunel D, Poncet C, Hochu I, Poirier S, Santoni S, Glemin S, David J (2007) Grinding up wheat: A massive loss of nucleotide diversity since domestication. Mol Biol Evol 24:1506-1517. doi:10.1093/molbev/msm077

Huang SX, Sirikhachornkit A, Faris JD, Su XJ, Gill BS, Haselkorn R, Gornicki P (2002)

Phylogenetic analysis of the acetyl-CoA carboxylase and 3-phosphoglycerate kinase loci in wheat and other grasses. Plant Mol Biol 48:805-820

Jiang J, Gill BS (1994) Different species-specific chromosome translocations in Triticum timopheevii and T. turgidum support the diphyletic origin of polyploid wheats. Chrom Res 2:59-64. doi: 10.1007/BF01539455

Kato A, Lamb JC, Birchler JA (2004) Chromosome painting using repetitive DNA sequences as probes for somatic chromosome identification in maize. Proc Natl Acad Sci USA 101:13554-13559. doi:10.1073/pnas.0403659101

Kato A, Albert PS, Vega JM, Birchler JA (2006) Sensitive fluorescence in situ hybridization signal detection in maize using directly labeled probes produced by high concentration DNA polymerase nick translation. Biotech \& Histochem 81:71-78. doi:10.1080/10520290600643677

Kawaura K, Mochida K, Enju A, Totoki Y, Toyoda A, Sakaki Y, Kai C, Kawai J, Hayashizaki Y, Seki M, Shinozaki K, Ogihara Y (2009) Assessment of adaptive evolution between wheat and rice as deduced from full-length common wheat cDNA sequence data and expression patterns. BMC Genomics 10:271 doi:10.1186/1471-2164-10-271

Kihara H (1944) Discovery of the DD-analyser, one of the ancestors of Triticum vulgare. Agric Hort 19:13-14

Kilian B, Ozkan H, Deusch O, Effgen S, Brandolini A, Kohl J, Martin W, Salamini F (2007) Independent wheat B and G genome origins in outcrossing Aegilops progenitor haplotypes. Mol Biol Evol 24:217-227. doi:10.1093/molbev/ms1151 
Kim JS, Childs KL, Islam-Faridi MN, Menz MA, Klein RR, Klein PE, Price HJ, Mullet JE, Stelly DM (2002) Integrated karyotyping of sorghum by in situ hybridization of landed BACs. Genome 45:402-412. doi: 10.1139/g01-141

Lamb JC, Danilova T, Bauer MJ, Meyer JM, Holland JJ, Jensen MD, Birchler JA (2007) Singlegene detection and karyotyping using small-target fluorescence in situ hybridization on maize somatic chromosomes. Genetics 175:1047-1058. doi:10.1534/genetics.106.065573

Li W, Zhang P, Fellers JP, Friebe B, Gill BS (2004) Sequence composition, organization, and evolution of the core Triticeae genome. Plant J 40:500-511. doi:10.1111/j.1365313X.2004.02228.X

Li Z, Sun F, Xu S, Chu X, Mukai Y, Yamamoto M, Ali S, Rampling L, Kosar-Hashemi B, Rahman S, Morell MK (2003) The structural organization of the gene encoding class II starch synthase of wheat and barley and the evolution of the genes encoding starch synthases in plants. Funct Integr Genomics 3:76-85. doi:10.1007/s10142-002-0072-4

Lysak MA, Fransz PF, Ali HB, Schubert I (2001) Chromosome painting in Arabidopsis thaliana. Plant J 28:689-697. doi: 10.1046/j.1365-313x.2001.01194.x

Ma L, Vu GTH, Schubert V, Watanabe K, Stein N, Houben A, Schubert I (2010) Synteny between Brachypodium distachyon and Hordeum vulgare as revealed by FISH. Chrom Res 18:841850. doi:10.1007/s10577-010-9166-3

Maestra B, Naranjo T (1999) Structural chromosome differentiation between Triticum timopheevii and T. turgidum and T. aestivum. Theor Appl Genet 98:744-750

Matsuoka Y (2011) Evolution of polyploid Triticum wheats under cultivation: the role of domestication, natural hybridization and allopolyploid speciation in their diversification. Plant Cell Physiol 52:750-764. doi:10.1093/pcp/pcr018

McFadden ES, Sears ER (1946) The origin of Triticum spelta and its free-threshing hexaploid relatives. J Hered 37:81 107 
Mickelson-Young L, Endo TR, Gill BS (1995) A cytogenetic ladder-map of the wheat homoeologous group-4 chromosomes. Theor Appl Genet 90:1007-1011

Miftahudin, Ross K, Ma XF, Mahmoud AA, Layton J, Milla MAR, Chikmawati T, Ramalingam J, Feril O, Pathan MS, Momirovic GS, Kim S, Chema Y, Fang P, Haule L, Struxness H, Birkes J, Yaghoubian C, Skinner R, McAllister J, Nguyen V, Qi LL, Echalier B, Gill BS, Linkiewicz AM, Dubcovsky J, Akhunov ED, Dvorak AJ, Dilbirligi M, Gill KS, Peng JH, Lapitan NLV, Bermudez-Kandianis CE, Sorrells ME, Hossain KG, Kalavacharla V, Kianian SF, Lazo GR, Chao S, Anderson OD, Gonzalez-Hernandez J, Conley EJ, Anderson JA, Choi DW, Fenton RD, Close TJ, McGuire PE, Qualset CO, Nguyen HT, Gustafson JP (2004) Analysis of expressed sequence tag loci on wheat chromosome group 4. Genetics 168:651663. doi:10.1534/genetics. 104.034827

Mochida K, Yoshida T, Sakurai T, Ogihara Y, Shinozaki K (2009) TriFLDB: A database of clustered full-length coding sequences from Triticeae with applications to comparative grass genomics. Plant Physiol 150:1135-1146. doi:10.1104/pp.109.138214

Mukai Y, Nakahara Y, Yamamoto M (1993) Simultaneous discrimination of the three genomes in hexaploid wheat by multicolor fluorescence in situ hybridization using total genomic and highly repeated DNA probes. Genome 36:489-494. doi: 10.1139/g93-067

Nagaki K, Tsujimoto H, Isono K, Sasakuma T (1995) Molecular characterization of a tandem repeat, Afa family, and distribution among Triticeae. Genome 38:479-486. doi 10.1139/g95-063

Nagaki K, Tsujimoto H, Sasakuma T (1998) Dynamics of tandem repetitive Afa-family sequences in Triticeae, wheat-related species. J Mol Evol 47:183-189

Naranjo T, Roca A, Goicoechea PG, Giraldez R (1987) Arm homoeology of wheat and rye chromosomes. Genome 29:873-882. doi: 0.1139/g87-149

Nesbitt M, Samuel D (1996) From staple crop to extinction? The archaeology and history of the hulled wheats. In: Padulosi S, Hammer K, Heller J (eds) Proc $1^{\text {st }}$ Intern Workshop on Hulled 
Wheats, Castelvecchio Pascoli, Tuscany, Italy, 21-22 July 1995. Intern Plant Genet Res Inst Rome, 41-100

Pedersen C, Rasmussen SK, LindeLaursen I (1996) Genome and chromosome identification in cultivated barley and related species of the Triticeae (Poaceae) by in situ hybridization with the GAA-satellite sequence. Genome 39:93-104. doi 10.1139/g96-013

Pedersen C, Langridge P (1997) Identification of the entire chromosome complement of bread wheat by two-colour FISH. Genome 40:589-593. doi: 10.1139/g97-077

Perez R, de Bustos A, Jouve N, Cuadrado A (2009) Localization of Rad50, a single-copy gene, on group 5 chromosomes of wheat, using a FISH protocol employing tyramide for signal amplification (Tyr-FISH). Cytogenet Genome Res 125:321-328. doi:10.1159/000235938

Podkowinski J, Sroga GE, Haselkorn R, Gornicki P (1996) Structure of a gene encoding a cytosolic acetyl-CoA carboxylase of hexaploid wheat. Proc Natl Acad Sci USA 93:1870-1874

Podkowinski J, Jelenska J, Sirikhachornkit A, Zuther E, Haselkorn R, Gornicki P (2003) Expression of cytosolic and plastid acetyl-coenzyme A carboxylase genes in young wheat plants. Plant Physiol 131:763-772. doi:10.1104/pp.013169

Pumphrey M, Bai J, Laudencia-Chingcuanco D, Anderson O, Gill BS (2009) Nonadditive expression of homoeologous genes is established upon polyploidization in hexaploid wheat. Genetics 181:1147-1157. doi:genetics.108.096941

Qi LL, Echalier B, Chao S, Lazo GR, Butler GE, Anderson OD, Akhunov ED, Dvorak J, Linkiewicz AM, Ratnasiri A, Dubcovsky J, Bermudez-Kandianis CE, Greene RA, Kantety R, La Rota CM, Munkvold JD, Sorrells SF, Sorrells ME, Dilbirligi M, Sidhu D, Erayman M, Randhawa HS, Sandhu D, Bondareva SN, Gill KS, Mahmoud AA, Ma XF, Miftahudin, Gustafson JP, Conley EJ, Nduati V, Gonzalez-Hernandez JL, Anderson JA, Peng JH, Lapitan NLV, Hossain KG, Kalavacharla V, Kianian SF, Pathan MS, Zhang DS, Nguyen HT, Choi DW, Fenton RD, Close TJ, McGuire PE, Qualset CO, Gill BS (2004) A 
chromosome bin map of 16,000 expressed sequence tag loci and distribution of genes among the three genomes of polyploid wheat. Genetics 168:701-712. doi:10.1534/genetics.104.034868

Rayburn AL, Gill BS (1985) Use of biotin-labeled probes to map specific DNA sequences on wheat chromosomes. J Hered 76:78-81

Rayburn AL, Gill BS (1986) Isolation of a D-genome specific repeated DNA sequence from Aegilops squarrosa. Plant Mol Biol Reporter 4:102-109. doi:10.1007/BF02732107

Rayburn AL, Gill BS (1987) Molecular analysis of the D-genome of the Triticeae. Theor Appl Genet 73:385-388. doi:10.1007/BF00262505

Rodriguez S, Perera E, Maestra B, Diez M, Naranjo T (2000) Chromosome structure of Triticum timopheevii relative to T. turgidum. Genome 43:923-930. doi: 10.1139/g00-062

Sasaki Y, Nagano Y (2004) Plant acetyl-CoA carboxylase: Structure, biosynthesis, regulation, and gene manipulation for plant breeding. Bioscience Biotech and Biochem 68:1175-1184 Schwarzacher T, Heslop-Harrison J (2000) Practical in situ hybridization. BIOS, Oxford, UK Schweizer GF, Baumer M, Daniel G, Rugel H, Roder MS (1995) RFLP markers linked to scald (Rhynchosporium. secalis) resistance gene Rh2 in barley. Theor Appl Genet 90:920-924. doi: 10.1007/BF00222904

Sears ER (1954) The aneuploids of common wheat. Agric Expt Stn Res Bull 572:1-58

Smit AFA, Hubley R, Green P (1996-2004) RepeatMasker Open-3.0. http://wwwrepeatmaskerorg Sorrells ME, La Rota M, Bermudez-Kandianis CE, Greene RA, Kantety R, Munkvold JD, Miftahudin, Mahmoud A, Ma XF, Gustafson PJ, Qi LLL, Echalier B, Gill BS, Matthews DE, Lazo GR, Chao SM, Anderson OD, Edwards H, Linkiewicz AM, Dubcovsky J, Akhunov ED, Dvorak J, Zhang DS, Nguyen HT, Peng JH, Lapitan NLV, Gonzalez-Hernandez JL, Anderson JA, Hossain K, Kalavacharla V, Kianian SF, Choi DW, Close TJ, Dilbirligi M, Gill KS, Steber C, Walker-Simmons MK, McGuire PE, Qualset CO (2003) Comparative 
DNA sequence analysis of wheat and rice genomes. Genome Res 13:1818-1827. doi:10.1101/Gr.1113003

Szakacs E, Molnar-Lang M (2007) Development and molecular cytogenetic identification of new winter wheat-winter barley ('Martonvasari 9 kr1'-'Igri') disomic addition lines. Genome 50:43-50. doi:10.1139/G06-134

Turnbull KM, Turner M, Mukai Y, Yamamoto M, Morell MK, Appels R, Rahman S (2003) The organization of genes tightly linked to the Ha locus in Aegilops tauschii, the D-genome donor to wheat. Genome 46:330-338. doi: 10.1139/g02-124

Turner M, Mukai Y, Leroy P, Charef B, Appels R, Rahman S (1999) The Ha locus of wheat: Identification of a polymorphic region for tracing grain hardness in crosses. Genome 42:1242-1250. doi: 10.1139/g99-075

Vershinin A, Svitashev S, Gummesson PO, Salomon B, Vonbothmer R, Bryngelsson T (1994) Characterization of a family of tandemly repeated DNS sequences in Triticeae. Theor Appl Genet 89:217-225. doi: 10.1007/BF00225145

Wang CJR, Harper L, Cande WZ (2006) High-resolution single-copy gene fluorescence in situ hybridization and its use in the construction of a cytogenetic map of maize chromosome 9. Plant Cell 18:529-544. doi:10.1105/tpc.105.037838

Werner JE, Endo TR, Gill BS (1992) Toward a cytogenetically based physical map of the wheat genome. Proc Natl Acad Sci USA 89:11307-11311

Woo SS, Jiang JM, Gill BS, Paterson AH, Wing RA (1994) Construction and characterization of a bacterial artificial chromosome library of Sorghum bicolor. Nucl Acids Res 22:4922-4931. doi:10.1093/nar/22.23.4922

Zhang P, Li W, Fellers J, Friebe B, Gill BS (2004a) BAC-FISH in wheat identifies chromosome landmarks consisting of different types of transposable elements. Chromosoma 112:288-299. doi:10.1007/s00412-004-0273-9 
Zhang P, Li W, Friebe B, Gill BS (2004b) Simultaneous painting of three genomes in hexaploid wheat by BAC-FISH. Genome 47:979-987. doi:10.1139/g04-042

Zhang Z, Schwartz S, Wagner L, Miller W (2000) A greedy algorithm for aligning DNA sequences. J Computational Biol 7:203-214 
Table 1 Acc-2 mapping and detecting copy number: comparison of FISH and results of Southern analysis of wheat aneuploidy stocks and genomic DNA sequence analysis (from Faris et al. 2001; Huang et al. 2002)

\begin{tabular}{|c|c|c|c|c|c|}
\hline Species, genome & $\begin{array}{l}\text { Accession } \\
\text { (origin) }\end{array}$ & $\begin{array}{l}\text { Number of } \\
\text { chromosomes } \\
\text { with } A c c-2 \\
\text { FISH signal }\end{array}$ & $\begin{array}{c}\text { Chromosomes with } A c c-2 \text { FISH signals } \\
\text { (chromosome specific cytological marker is } \\
\text { described) }\end{array}$ & $\begin{array}{l}\text { Position on } \\
\text { chromosome } \\
\text { and copy } \\
\text { number (Faris } \\
\text { et al., 2001; } \\
\text { Huang et al., } \\
\text { 2002) } \\
\end{array}$ & $\begin{array}{c}\text { C-banded } \\
\text { karyotypes } \\
\text { used for } \\
\text { chromosomes } \\
\text { identification }\end{array}$ \\
\hline $\begin{array}{l}\text { T. aestivum } \\
\text { AABBDD }\end{array}$ & $\begin{array}{l}\text { Chinese } \\
\text { Spring } \\
\text { Wichita } \\
\text { (USA) } \\
\text { TAM107 } \\
\text { (USA) }\end{array}$ & 10 & $\begin{array}{l}\text { 3AL (two copies), 4AL; } \\
\text { 3BL; } \\
\text { 3DL, 5DL } \\
\text { The same as Chinese Spring; } \\
\text { 4AL - } 2 \text { Acc-2 copies* } \\
\text { The same as Chinese Spring; } \\
\text { 3BL - } 2 \text { Acc-2 copies* }\end{array}$ & $\begin{array}{l}\text { 3AL, } \\
\text { 3BL, } \\
\text { 3DL, 5DL } \\
6 \text { sequences }\end{array}$ & $\begin{array}{l}\text { (Gill et al., } \\
\text { 1991; Friebe } \\
\text { et al. 1996) }\end{array}$ \\
\hline $\begin{array}{l}\text { T. urartu } \\
\text { AA }\end{array}$ & TA766 & 6 & $\begin{array}{l}\text { 1AL (NOR, FLcDNAs 1S-1, 1L-2, co- } \\
\text { localized with GAA on 1S), } \\
\text { 3AL (FLcDNA 3S-2, co-localized with } \\
\text { GAA), } \\
\text { 4AL (FLcDNAs 4S-1, 4L-1 co-localized with } \\
\text { Acc-2 probe) }\end{array}$ & $\begin{array}{l}3 \text { sequences } \\
\text { (TA763, } \\
\text { Lebanon) }\end{array}$ & $\begin{array}{l}\text { (Friebe and } \\
\text { Gill 1996) }\end{array}$ \\
\hline $\begin{array}{l}\text { T. monococcum } \\
\text { AA }\end{array}$ & $\begin{array}{l}\text { TA2025 } \\
\text { (Turkey) }\end{array}$ & 6 & $\begin{array}{l}\text { 1AL (NOR, FLcDNAs 1S-1, 1L-2, co- } \\
\text { localized with Acc } 2 \text { probe), } \\
\text { 3AL (FLcDNAs } 3 \text { S-1, 3S-2, co-localized } \\
\text { with Acc-2 probe), } \\
\text { 4AL (FLcDNAs 4S-1, 4L-1 co-localized with } \\
\text { (GAA) }\end{array}$ & 3 sequences & $\begin{array}{l}\text { (Friebe et al. } \\
1990 \text { ) }\end{array}$ \\
\hline $\begin{array}{l}\text { Ae. speltoides } \\
\text { SS }\end{array}$ & $\begin{array}{l}\text { TA2368 } \\
\text { (Turkey) } \\
\text { TA2780 } \\
\text { (Israel) }\end{array}$ & $\begin{array}{l}5 \\
4\end{array}$ & $\begin{array}{l}\text { 1SL (NOR), no pair - heterozygous plant, } \\
\text { 3SL, 5SL,(GAA, arm ratio) } \\
\text { 3SL, 5SL (GAA, arm ratio) }\end{array}$ & $\begin{array}{l}2 \text { sequences } \\
-\end{array}$ & $\begin{array}{l}\text { (Friebe and } \\
\text { Gill, 1996; } \\
\text { Friebe et al. } \\
\text { 2000) }\end{array}$ \\
\hline $\begin{array}{l}\text { Ae. tauschii } \\
\text { DD }\end{array}$ & $\begin{array}{c}\text { TA1691 } \\
\text { (Unknown) }\end{array}$ & 4 & $\begin{array}{l}\text { 3DL (pAs1), 5DL (NOR, pAs1, DAPI } \\
\text { heterochromatic block on 5DS near the } \\
\text { centromere) }\end{array}$ & $\begin{array}{l}\text { 3DL, 5DL } \\
2 \text { sequences }\end{array}$ & $\begin{array}{l}\text { (Friebe and } \\
\text { Gill 1996) }\end{array}$ \\
\hline $\begin{array}{l}\text { T.turgidum } \\
\text { subsp. } \\
\text { dicoccoides } \\
\text { AABB }\end{array}$ & $\begin{array}{l}\text { TA73 } \\
\text { (Lebanon) } \\
\text { TA1385 } \\
\text { (Iraq) } \\
\text { TA1392 } \\
\text { (Israel) } \\
\text { TA84 } \\
\text { (Turkey) } \\
\end{array}$ & $\begin{array}{l}10 \\
8 \\
10 \\
8\end{array}$ & $\begin{array}{l}\text { 3AL, 4AL, 1BL, 3BL, 5BL } \\
\text { 3AL, 4AL, 3BL, 5BL } \\
\text { 3AL, 4AL, 1BL, 3BL, 5BL } \\
\text { 3AL, 4AL, 3BL, 5BL }\end{array}$ & $\begin{array}{l}3 \text { sequences } \\
- \\
2 \text { sequences } \\
2 \text { sequences }\end{array}$ & $\begin{array}{l}\text { (Dedkova et } \\
\text { al. 2007) }\end{array}$ \\
\hline $\begin{array}{l}\text { T.turgidum } \\
\text { subsp. dicoccum } \\
\text { AABB }\end{array}$ & $\begin{array}{l}\text { TA10492 } \\
\text { (Ethiopia) }\end{array}$ & 8 & 3AL, 4AL, 1BL, 3BL & - & $\begin{array}{l}\text { (Gill et al., } \\
\text { 1991; Friebe } \\
\text { and Gill } \\
\text { 1996) }\end{array}$ \\
\hline
\end{tabular}




\begin{tabular}{|c|c|c|c|c|c|}
\hline $\begin{array}{l}\text { T.turgidum } \\
\text { subsp. durum } \\
\text { AABB }\end{array}$ & $\begin{array}{c}\text { Langdon } \\
\text { Durum (USA) } \\
\text { TA2932 } \\
\text { Kamut } \\
\text { Durum } \\
\text { (unknown) } \\
\text { TA9137 } \\
\text { cv. Bozak } \\
\text { (Azerbaijan) }\end{array}$ & 6 & $\begin{array}{l}\text { 3AL, 4AL, 3BL } \\
\text { The same as Langdon Durum } \\
\text { The same as Langdon Durum }\end{array}$ & - & $\begin{array}{l}\text { (Gill et al., } \\
\text { 1991; Friebe } \\
\text { and Gill } \\
\text { 1996) }\end{array}$ \\
\hline $\begin{array}{l}\text { T.timopheevii } \\
\mathrm{A}^{\mathrm{t}} \mathrm{A}^{\mathrm{t}} \mathrm{GG}\end{array}$ & $\begin{array}{c}\text { TA103 } \\
\text { (Yugoslavia) }\end{array}$ & 10 & 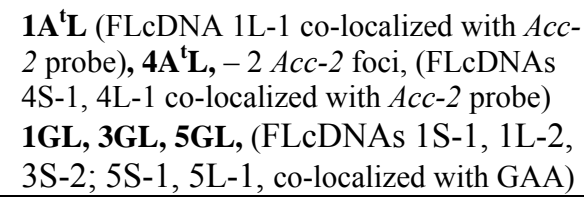 & 3 sequences & $\begin{array}{l}\text { (Badaeva et } \\
\text { al. 1994) }\end{array}$ \\
\hline
\end{tabular}

* On some chromosomal spreads it is possible to distinguish two sites of Acc-2 probe hybridization on the same chromatid of a chromosome which can be the evidence of multiple copies of the gene present on the same chromosome (Supplemental figure 6).

Table 2. Oligonucleotide FISH probes and Acc-2 pooled probe

\begin{tabular}{|c|c|c|c|c|}
\hline \# & Probe & Sequence $\left(5^{\prime}-3^{\prime}\right)$ and flourochrome label & $\begin{array}{l}\text { Amount } \\
\text { applied to } \\
\text { preparation, ng }\end{array}$ & $\begin{array}{l}\text { Sequence used to } \\
\text { develop probes }\end{array}$ \\
\hline \multirow[t]{2}{*}{1} & 6-FAM-GAA & 6-FAM-AAGAAGAAGAAGAAGAAGAAGAAGAA & 0.5 & \\
\hline & Cy5-GAA & Cy5- AAGAAGAAGAAGAAGAAGAAGAAGAA & 5 & \\
\hline 2 & pAs1-1 & 6-FAM-CAAAACGGACAATCTCTTTCAAAGTATCAGG & \multirow{2}{*}{$\begin{array}{l}\text { mixture, } 100 \mathrm{ng} \\
\text { each }\end{array}$} & \multirow{2}{*}{$\begin{array}{l}\text { D30736 (Rayburn and Gill } \\
\text { 1986; Nagaki et al. 1995), } \\
\text { X76300 (Vershinin et al. } \\
\text { 1994) }\end{array}$} \\
\hline 3 & pAs1-2 & 6-FAM-TCAGAGTTCATTTGAAATGCTTTTCA & & \\
\hline 4 & NOR & 6-FAM-TGGCGCGCGTCAACTTCCGTC & 100 & $\begin{array}{l}\text { X07841 (pTa71) (Barker et } \\
\text { al. 1988) }\end{array}$ \\
\hline 5 & pTa71 & Fluorescein labeled plasmid with $9 \mathrm{~kb}$ insert & 100 & $\begin{array}{l}\text { (Gerlach and Bedbrook } \\
\text { 1979) }\end{array}$ \\
\hline 6 & $5 \mathrm{Sg}$ & 6-FAM-CTACTCTCGCCCAAGCACGCTTAAC & \multirow{2}{*}{$\begin{array}{l}\text { mixture, 200ng } \\
\text { each }\end{array}$} & $\begin{array}{l}\text { AY841019, AY841026, } \\
\text { AJ409522, AY316207, } \\
\text { FJ882469 }\end{array}$ \\
\hline 7 & $5 \mathrm{Ssp}$ & 6-FAM-TGTTACCCCCGTCTTCGTCCCTTAT & & FJ882469, AJ409522 \\
\hline 8 & Acc-2 (pooled) & RT PCR Primers: & & \\
\hline $1 \mathrm{c}$ & $1950 \mathrm{bp}$ & $\begin{array}{ll}\mathrm{F} & \text { ACAATGGGATGGCTGCGGTCAAG } \\
\mathrm{R} & \text { CATCCGCGACCAAAAACCGAAGAA } \\
\end{array}$ & \multirow{3}{*}{$\begin{array}{l}\text { mixture, 150ng } \\
\text { each }\end{array}$} & U10187 \\
\hline $2 \mathrm{c}$ & $1942 b p$ & $\begin{array}{ll}\mathrm{F} & \text { CAACCCGACTCCCGAAAGAT } \\
\mathrm{R} & \text { GGGTCCTCCACTTCTCGGTAAATA }\end{array}$ & & U10187 \\
\hline $3 c$ & $2078 b p$ & $\begin{array}{ll}\mathrm{F} & \text { GCAGAATCTAACGAGCATAACCAG } \\
\mathrm{R} & \text { GTTTCAGCGAGATGCGACA } \\
\end{array}$ & & U10187 \\
\hline
\end{tabular}


Table 3. Full length cDNA FISH probes used for chromosome identification

\begin{tabular}{|l|l|l|l|l|l|}
\hline $\begin{array}{l}\text { FISH } \\
\text { probe }\end{array}$ & $\begin{array}{l}\text { FLcDNA, } \\
\text { KOMUGI } \\
\text { database }\end{array}$ & Matching EST & $\begin{array}{l}\text { EST position on bin } \\
\text { map }\end{array}$ & $\begin{array}{l}\text { Position of FISH signal on } \\
\text { chromosomes of cv Chinese Spring }\end{array}$ & $\begin{array}{l}\text { cDNA/probe } \\
\text { length, bp }\end{array}$ \\
\hline 1L-1 & tplb0013a02 & BF482555 & C-1BL6-0.32 & 1AL, 1BL, 1DL centromeric & 5094 \\
\hline 1L-2 & tplb0029f23 & BE591501 & $\begin{array}{l}\text { 1A? } \\
\text { 1BL6-0.32-0.47 } \\
\text { 1DL2-0.41-1.00 }\end{array}$ & 1AL, 1BL, 1DL distal end & 3113 \\
\hline 1S-1 & tplb0048d21 & BE425354 & $\begin{array}{l}\text { 1AS1-0.47-0.86 } \\
\text { 1DS3-0.48 }\end{array}$ & 1AS, 1BS, 1DS centromeric & 3487 \\
\hline 3S-1 & tplb0011e24 & BF200563 & $\begin{array}{l}\text { 3AS4-0.45-1.00 } \\
\text { 3DS3-0.33-0.57 }\end{array}$ & 3AS, 3BS, 3DS interstitial & 1491 \\
\hline 3S-2 & tplb0004j16 & BF202364 & $\begin{array}{l}\text { 3AS4-0.45-1.00 } \\
\text { 3DS3-0.24-0.55 }\end{array}$ & 3AS, 3BS, 3DS interstitial & 4402 \\
\hline 4S-1 & tplb0017g02 & BF485337 & $\begin{array}{l}\text { C-4AL11-0.66* } \\
\text { 4DS2-0.82-1.00 }\end{array}$ & $\begin{array}{l}\text { 4AL in the middle, 4BS, 4DS distal } \\
\text { end }\end{array}$ & 3191 \\
\hline $5 \mathrm{~L}-1$ & tplb0027f03 & BF482732 & $\begin{array}{l}\text { 3AL3-0.42-0.78 } \\
\text { 3DL2-0.27-0.81 }\end{array}$ & $\begin{array}{l}\text { 5AS interstitial, 5BS, 5DS distal } \\
\text { end }\end{array}$ & 2416 \\
\hline
\end{tabular}




\section{Figures}

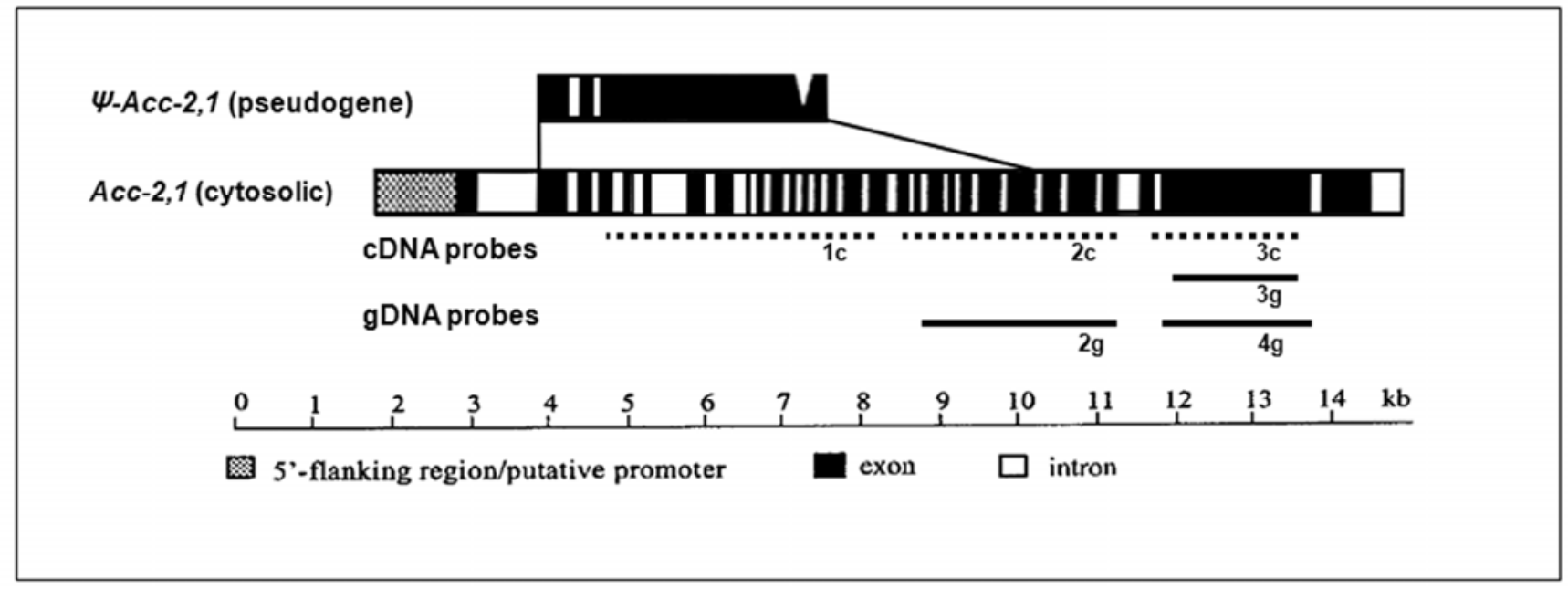

Figure 1 Positions of $A c c-2$ FISH probes developed based on cDNA and gDNA sequences. The structure of the Acc-2 gene and pseudogene is shown (adapted from (Faris et al. 2001)); cDNA probes were produced by RT PCR, gDNA probes were produced by PCR with gDNA as a template.

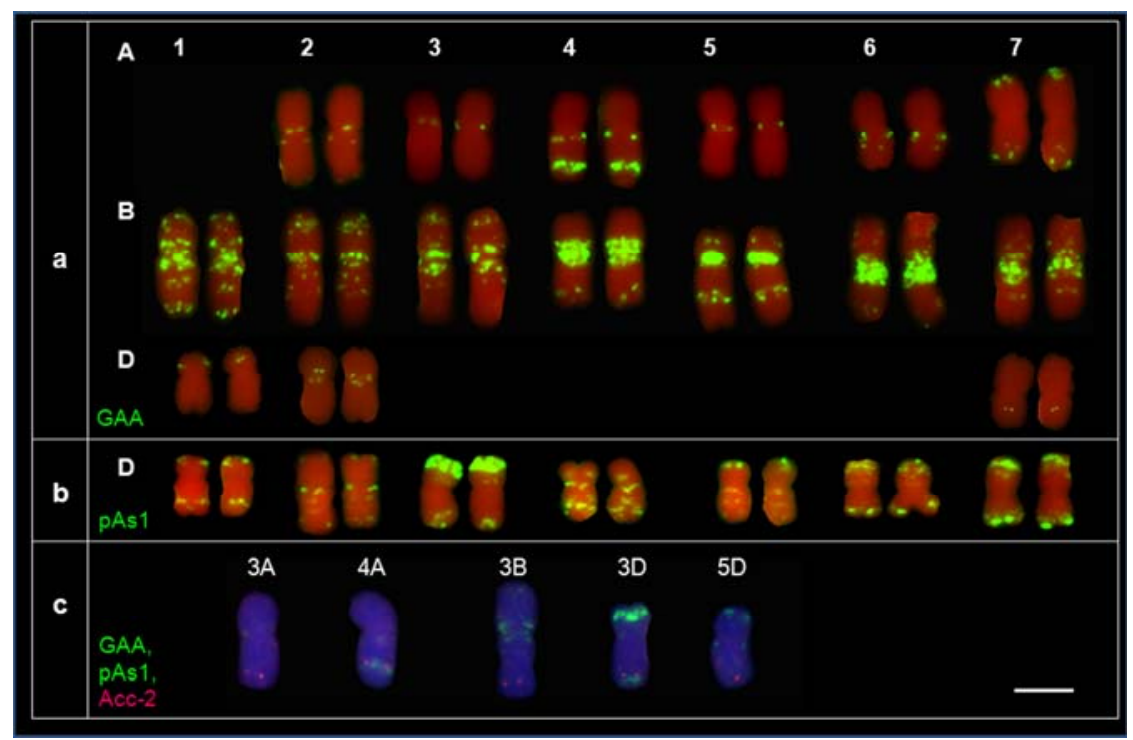

Figure 2 a, b FISH karyotype of cv Chinese Spring : a. GAA-oligonucleotyde probe pattern on A-, B- and D-genome chromosomes; b. pAs1-oligonucleotyde probe pattern on chromosomes of D genome; c. mapping of $A c c 2$ gene on wheat chromosomes. The $A c c-2$ probe is red, GAA and pAs1 repeats are green, chromosomes are counterstained with DAPI (blue); bar corresponds to $5 \mu \mathrm{m}$. 

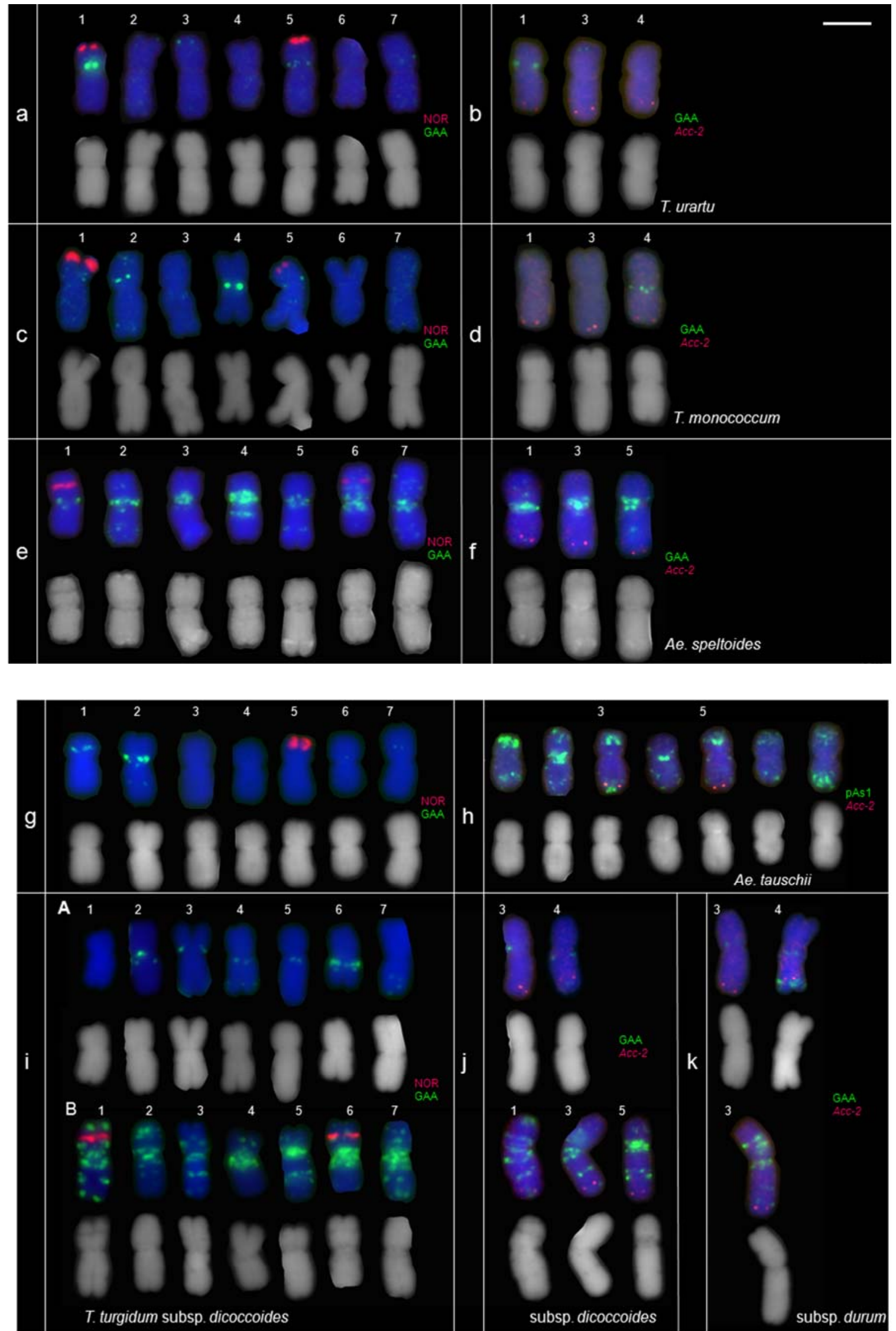

Fig. 3 (continued) 


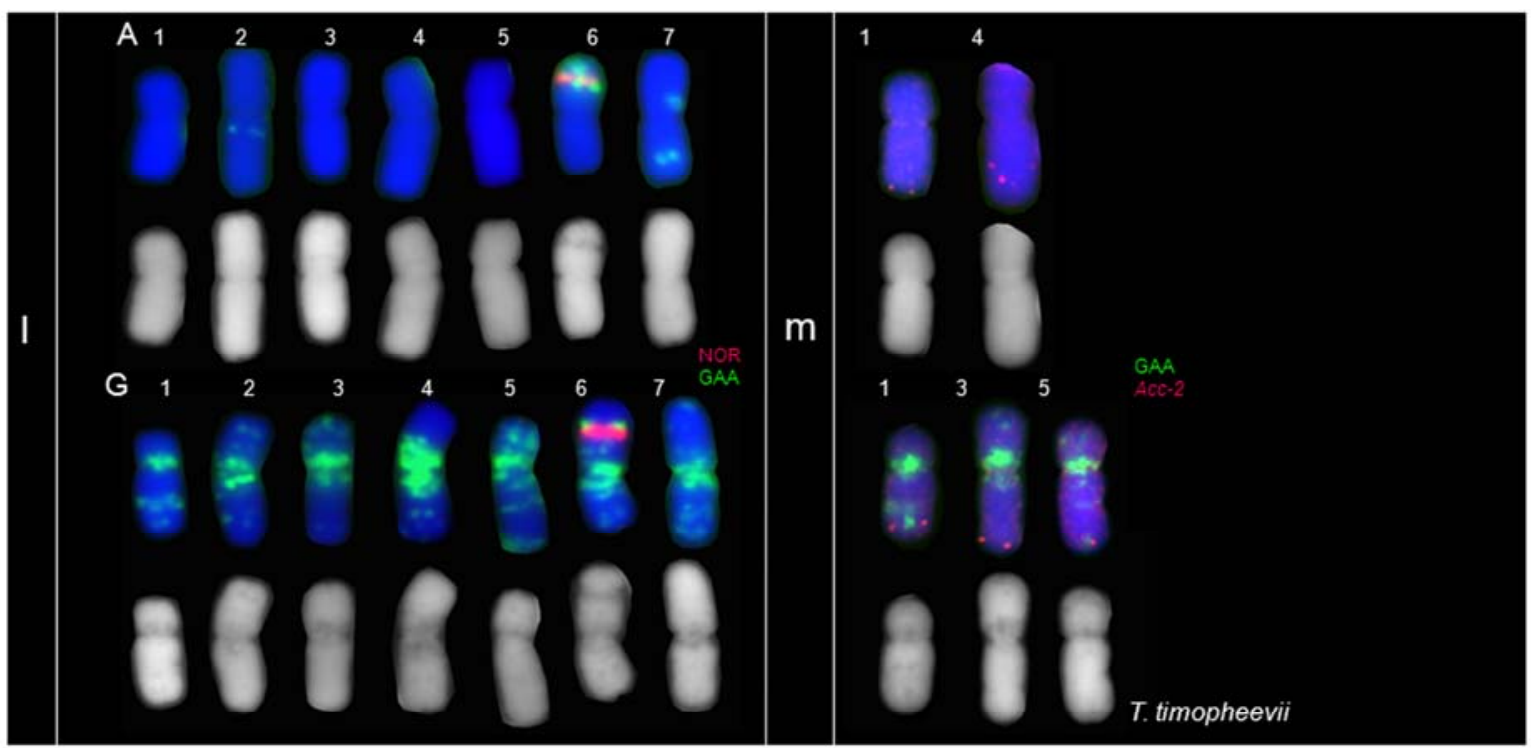

Fig. 3 (continued)

Figure 3 Identification of chromosomes of wheat species and mapping Acc-2 sequences using FISH with GAA and NOR probes. Each panel presents merged images of chromosomes and DAPI channel only. Left panels present karyotypes with GAA probe in green and NOR probe (pTa71) in red. Right panels present chromosomes with $A c c-2$ signals (red) and GAA (green), except panel h, where green is pAs1 repeat.

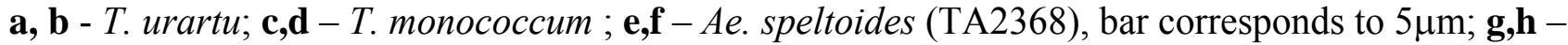
Ae. tauschii; $\mathbf{i}, \mathbf{j}-$ T. turgidum subsp. dicoccoides (TA73), $\mathbf{k}-$ T. turgidum subsp. durum(Langdon Durum); l,m - T. timopheevii. 


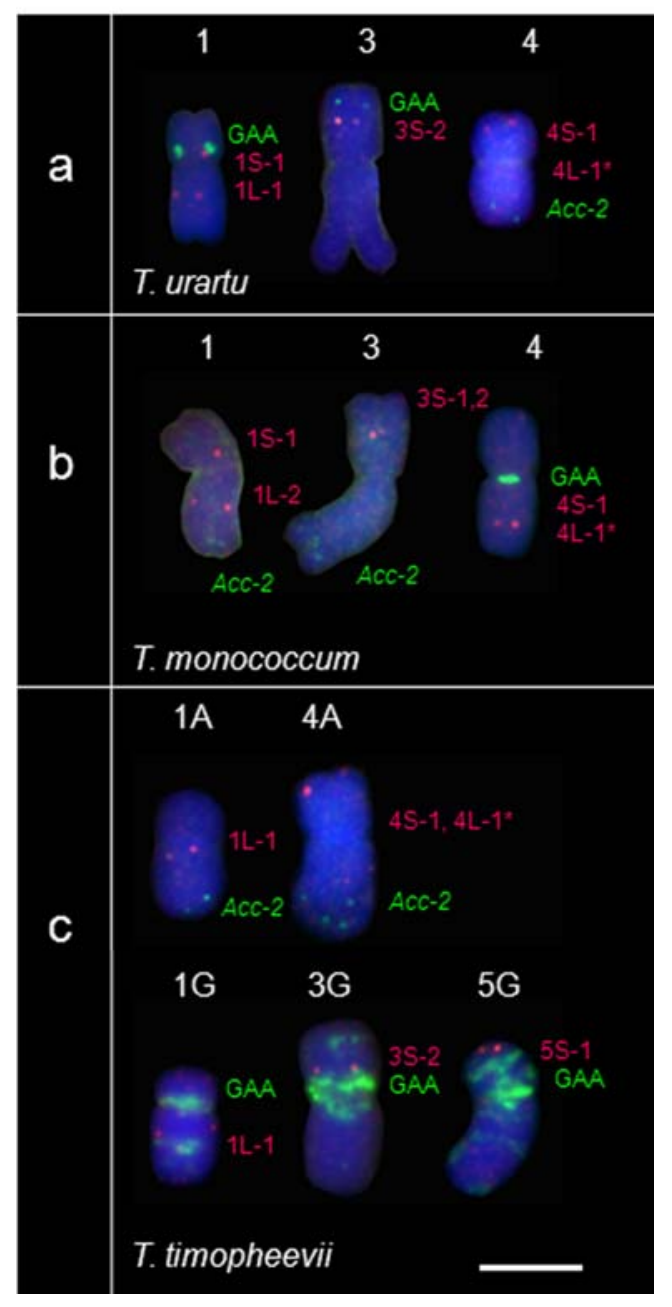

Figure 4 Identification of chromosomes of wheat species using FLcDNA probes.

a. T. urartu, probes: ch. 1: GAA - green, FLcDNAs probes 1S-1, 1L-2 - red; ch. 3: GAA - green, FLcDNA 3S-2 - red, ch. 4: FLcDNAs 4S-1, 4L-1 - red, Acc-2 - green.

b. T. monococcum: ch. 1: FLcDNAs 1S-1, 1L-2 - red, Acc-2 green, ch. 3: FLcDNAs 3S-1, 3S-2 - red, Acc-2 green; ch. 4: GAA green, FLcDNAs 4S-1, 4L-1 - red.

c. T. timopheevii : ch. 1A: FLcDNA 1L-1 is red, Acc-2 is green; ch. 4A: FLcDNAs 4S-1, 4L-1 are red, Acc-2 is green; chromosomes 1G, 3G, 5G: GAA is green, FLcDNAs 1S-1, 1L-2; 3S-2; 5L-1, 5S1 respectively, are red; bar corresponds to $5 \mu \mathrm{m}$. * Probes $4 \mathrm{~S}-1$ or $4 \mathrm{~L}-1$ where applied together.

Because it is not known whether chromosome $4 \mathrm{~A}$ of these three species has inversions, we can not say which of the probes produce signal on the long or short arm. 


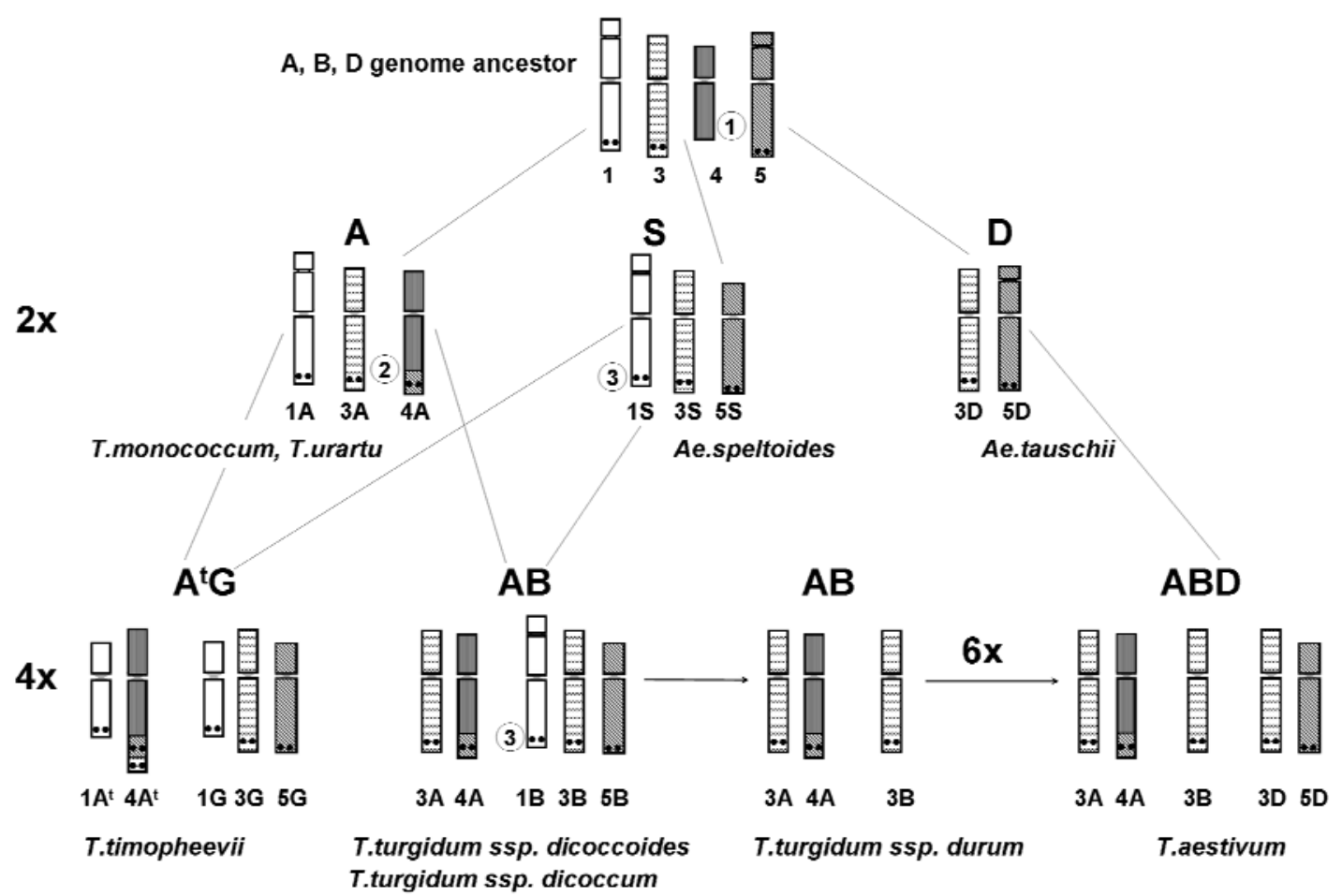

Figure 5 Chromosome modifications in wheat and Aegilops species as revealed by Acc-2 FISH mapping. 1. A translocation $4 \mathrm{AL} / 5 \mathrm{AL}$ occurred at A-genome ancestor and present in $\mathrm{A}$ genomes of all species studied. 2. 3AL/4AL translocation present in tetraploids of group Timopheevii. 3. Sgenomes and B-genomes are polymorphic in presence / absence of Acc-2 foci on chromosome arm 1L and 5L. Solid dots represent locations of $A c c-2$ foci. NORs are shown on chromosomes 1 and 5. 


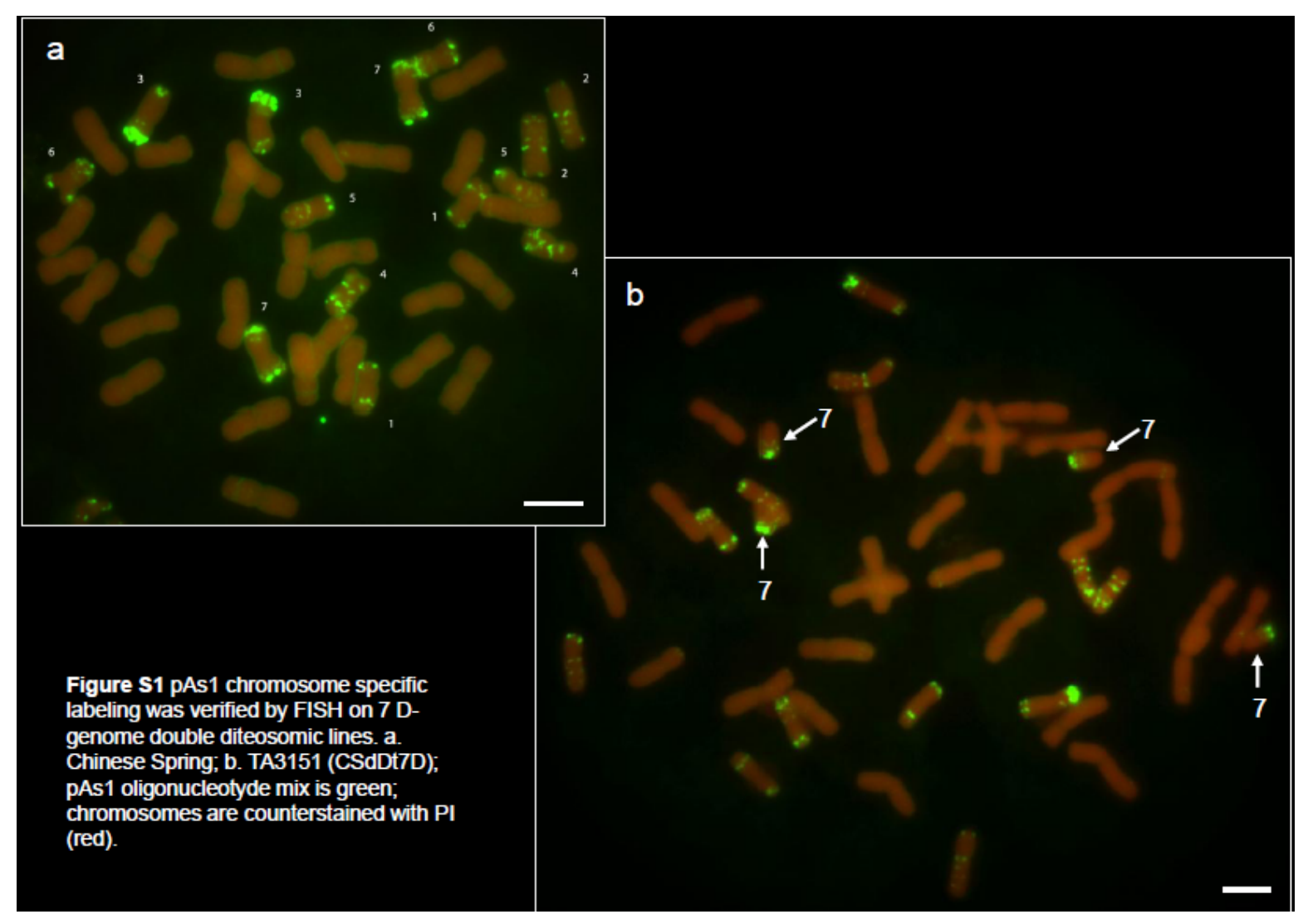

Supplemental figure 1 pAs1 chromosome specific labeling was verified by FISH on 7 D-genome double ditelosomic lines. a. Chinese Spring; b. TA3151 (CSdDt7D). Green - pAs1 oligo mix; chromosomes are counterstained with PI (red); bar corresponds to $5 \mu \mathrm{m}$. 


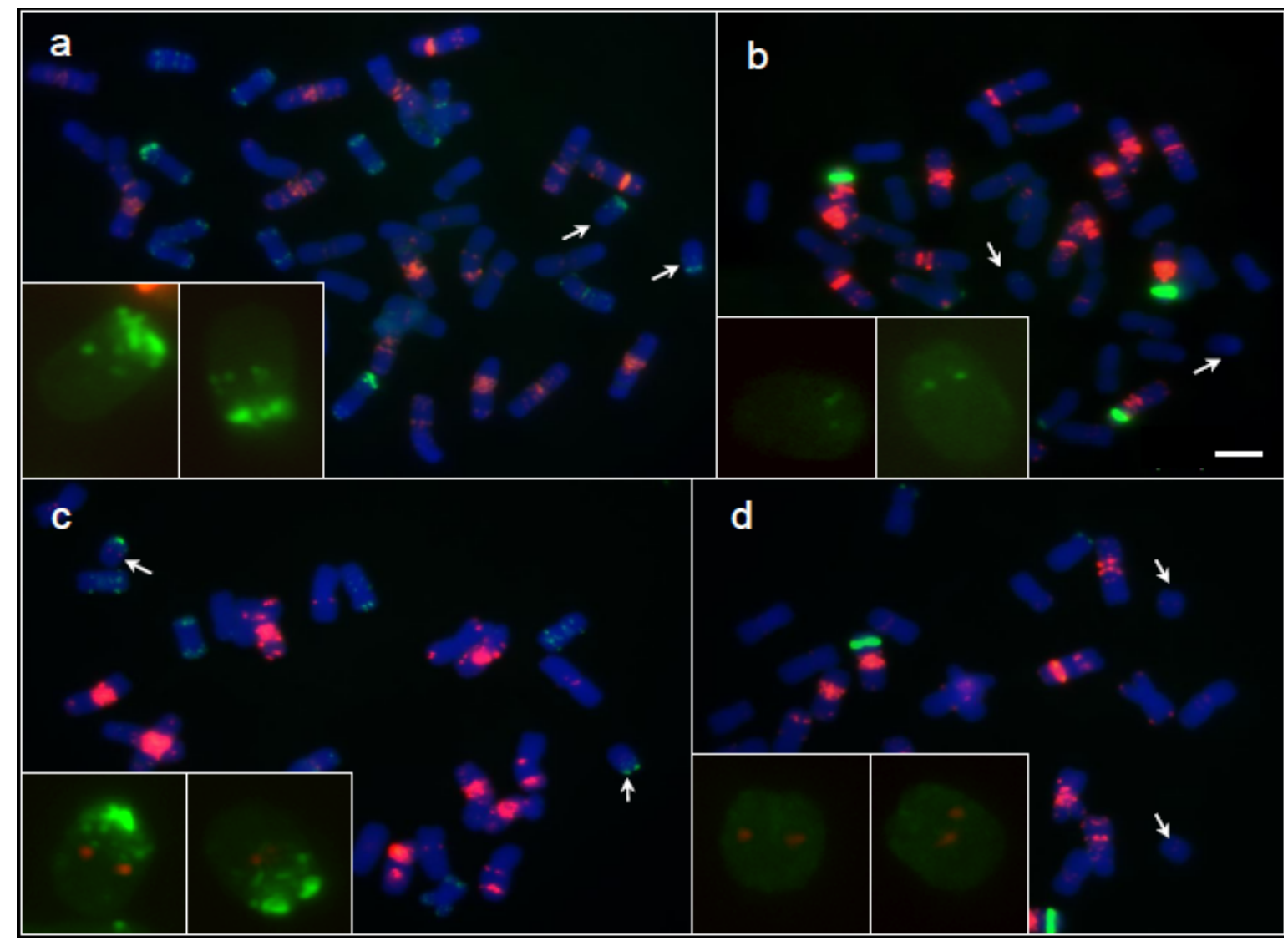

Supplemental figure 2 Identification of 7DS and 7DL chromosome arms using ditelosomic lines originated from Chinese Spring. Telosomes are shown with arrows. The physically shorter arm of chromosome 7D is homeologous to the long arms of chromosomes 7A and 7B (Werner et al., 1992). To verify GAA and pAs1 arm specific FISH pattern for chromosome 7D, two aneuploid ditelosomic lines originated from cultivar Canthatch and Chinese Spring were used. a. On both aneuploids genetically short arm of chromosome 7D has major distal pAs1 band and distinguishable minor pAs1 signal in the middle of the arm. b. As it was reported before (Friebe et al., 1996), 7DS arm has minor NOR signal which was confirmed by FISH with pTa71 probe. c,d. Genetically long arm of 7D also has major distal pAs1 band, no distinguishable minor pAs1 signals in the middle of the arm and no NOR signals, but there is a minor GAA signal in the middle of the arm.

a, b TA3130 CS Dt7DS; c, d TA3071 CS Dt7DL. Probes: GAA is red; a, c. pAs1 is green; b, d pTa71 is green; bar corresponds to $5 \mu \mathrm{m}$. 


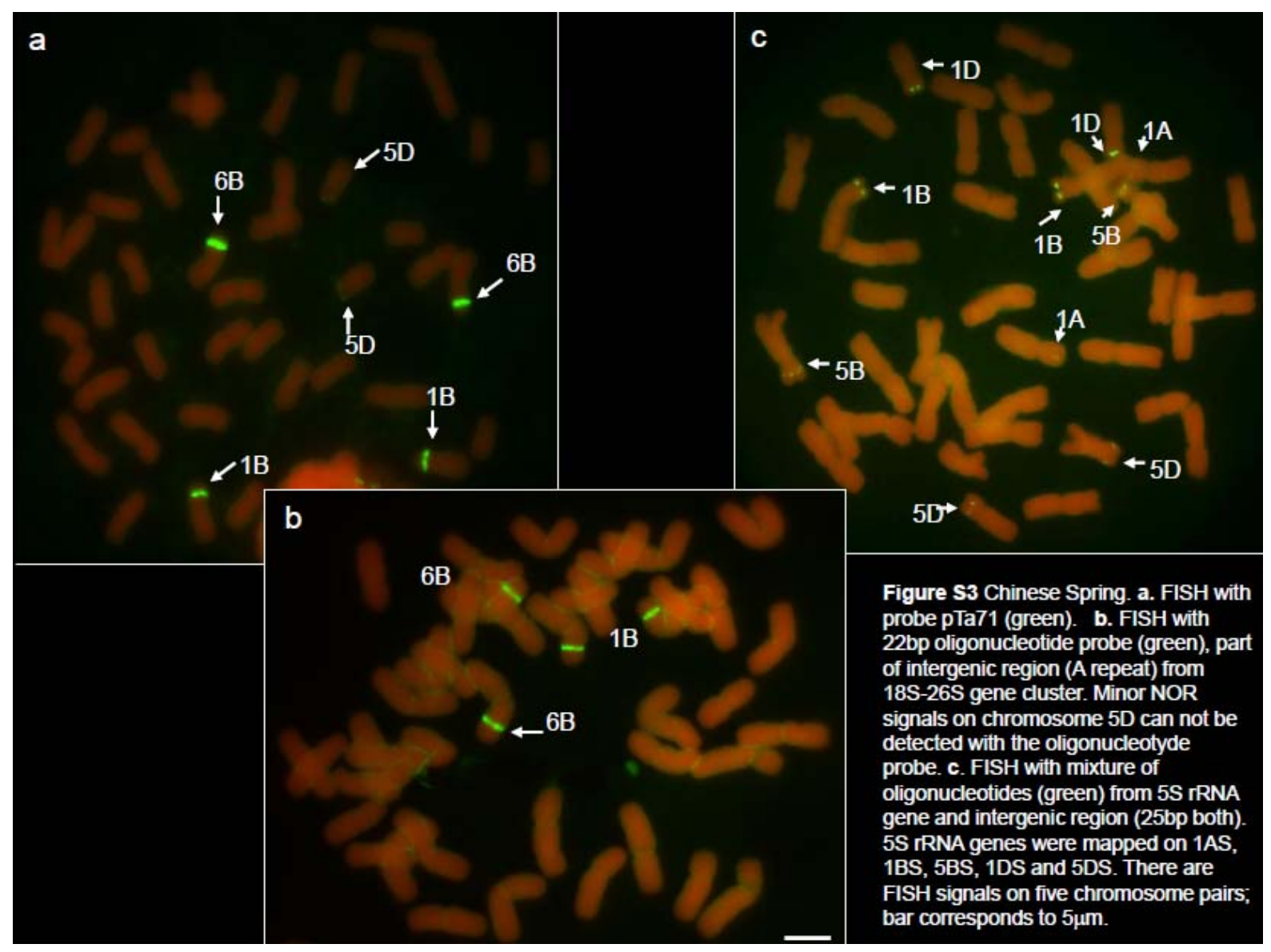

Supplemental figure 3 Chinese Spring. a. FISH with probe pTa71 (green). b. FISH with 22bp

oligonucleotide probe (green), part of intergenic region (A repeat) from 18S-26S gene cluster. Minor NOR signals on chromosome 5D can not be detected with the oligonucleotyde probe. c. FISH with mixture of oligonucleotides (green) from $5 \mathrm{~S} \mathrm{rRNA}$ gene and intergenic region (25bp both). $5 \mathrm{~S}$ rRNA genes were mapped on 1AS, 1BS, 5BS, 1DS and 5DS. There are FISH signals on five chromosome pairs; bar corresponds to $5 \mu \mathrm{m}$. 


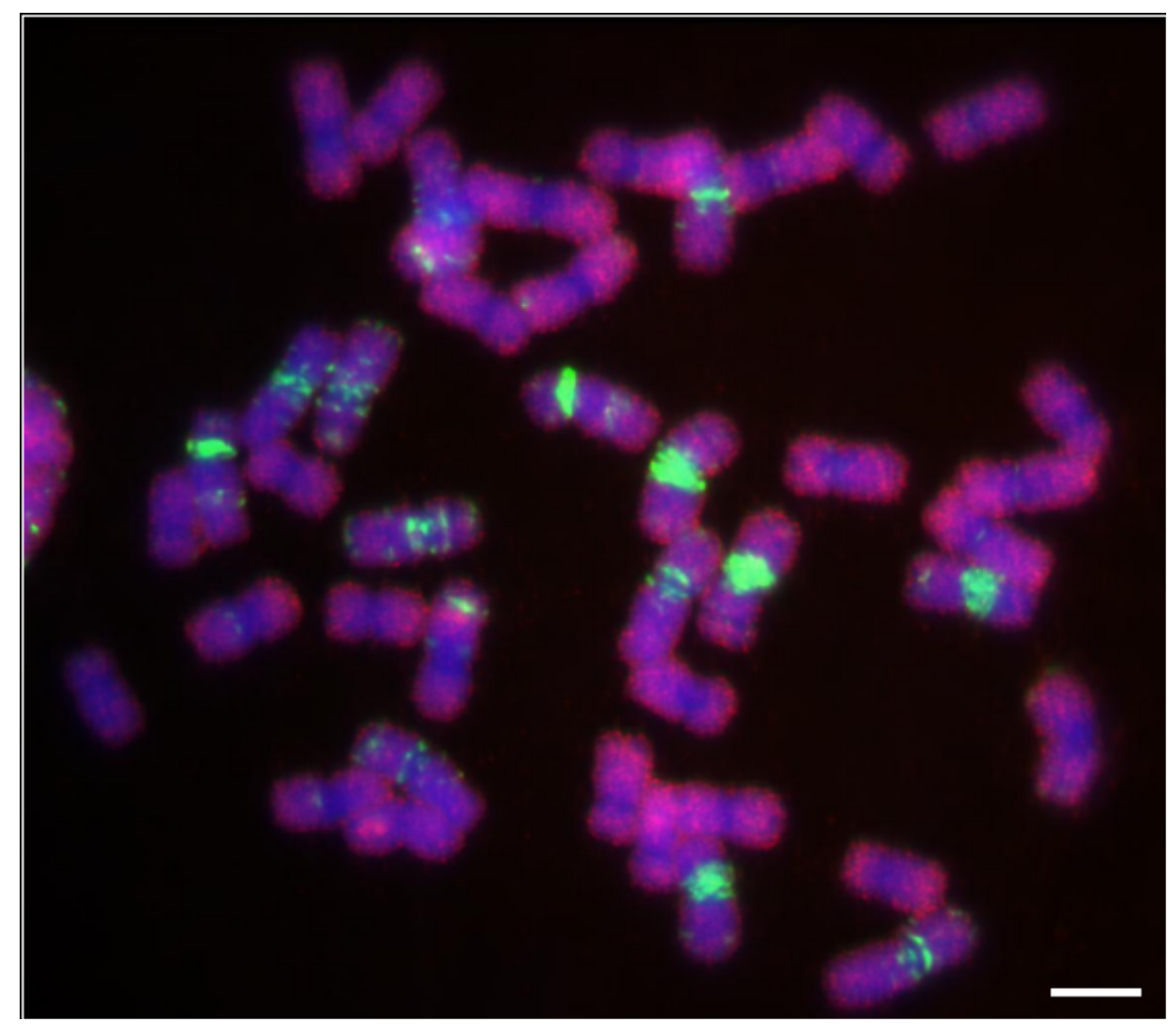

Figure S4 FISH with $A c c-2$ gDNA probe $2 \mathrm{~g}$ (red) produce staining on all chromosomes; GAA oligo probe is green; Chinese Spring; bar corresponds to $5 \mu \mathrm{m}$. 


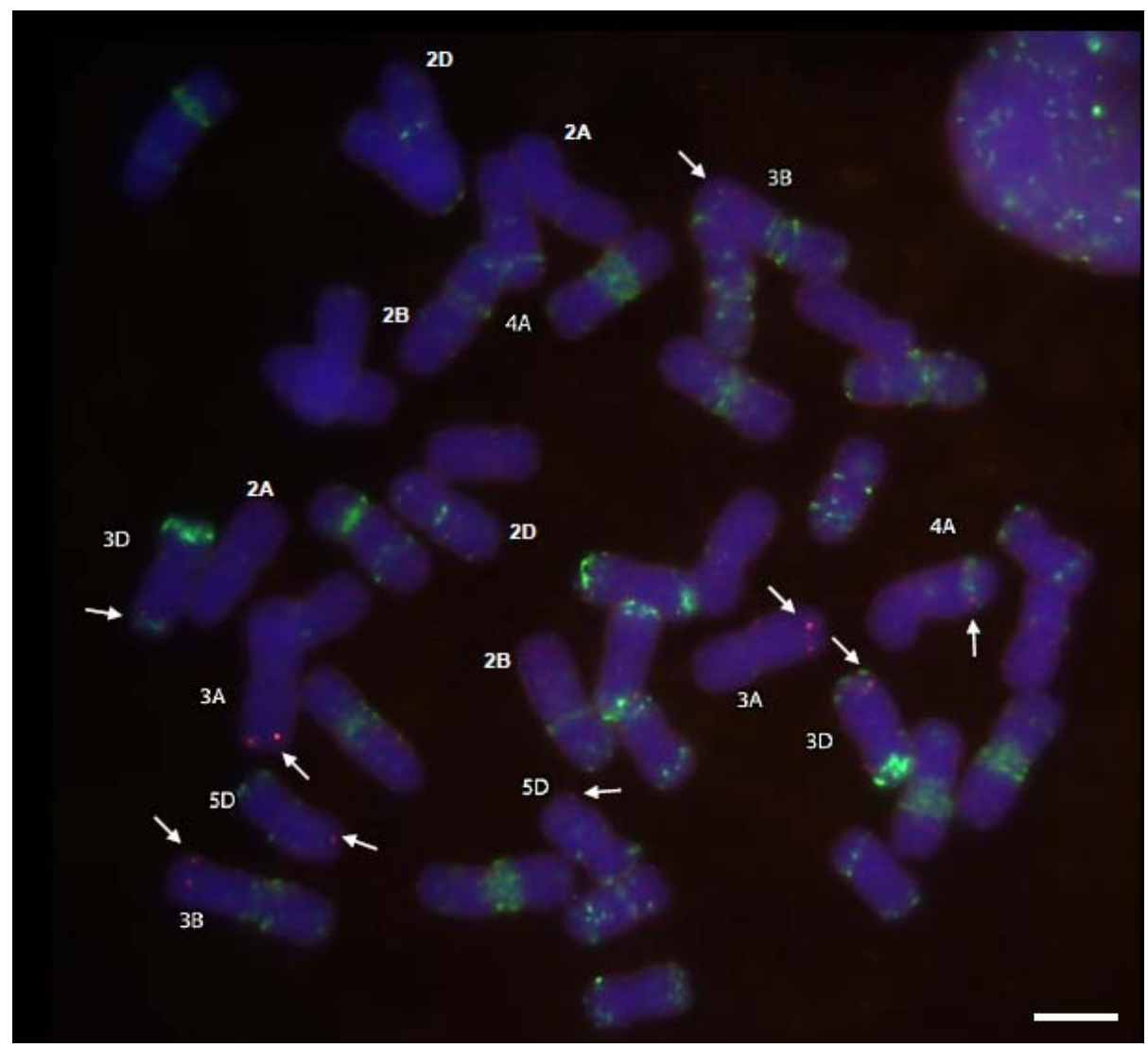

Figure S5 FISH with $A c c-2$ cDNA pooled probe $(6 \mathrm{~kb})$ on metaphase spread of cv. Chinese Spring. Acc-2 probe is red, GAA and pAS1 repeats are green; chromosomes are counterstained with DAPI (blue). Acc-2 signals are present on the long arms of chromosomes of group 3, 4AL and 5DL; bar corresponds to $5 \mu \mathrm{m}$. 


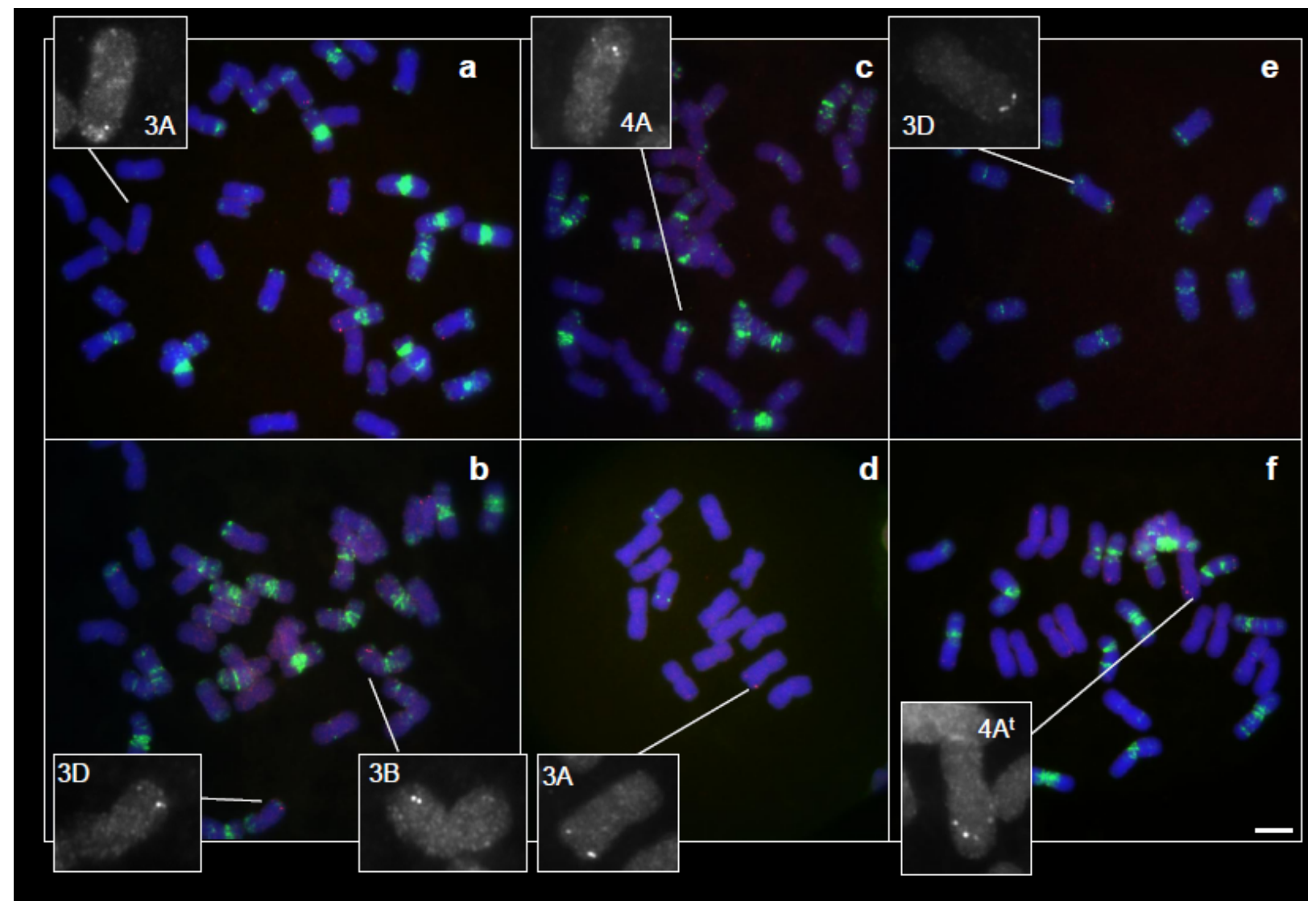

Figure S6 Double signals of Acc-2 probe (red). T. aestivum: a Chinese Spring, b Wichita, c TAM107; d T. urartu, e Ae. tauschii, f T. timopheevii. Green oligonucleotide probes are: a-c GAA and pAs1, e pAs1, d,f GAA; bar corresponds to $5 \mu \mathrm{m}$. 